UNIVERSIDADE DE SÃO PAULO

INSTITUTO DE PSICOLOGIA

\title{
DESENVOLVIMENTO E VALIDAÇÃO DE UMA FERRAMENTA COMPUTACIONAL PARA MENSURAÇÃO DAS CURVATURAS DA COLUNA VERTEBRAL
}

ANDRÉ LUIS ALARCON DO PASSO SUAIDE

SÃO PAULO

2008 


\section{DESENVOLVIMENTO E VALIDAÇÃO DE UMA FERRAMENTA COMPUTACIONAL PARA MENSURAÇÃO DAS CURVATURAS DA COLUNA VERTEBRAL}

ANDRÉ LUIS ALARCON DO PASSO SUAIDE

Dissertação apresentada ao Instituto de Psicologia da Universidade de São Paulo como requisito parcial para a obtenção do grau de Mestre em Neurociências e Comportamento. 
AUTORIZO A REPRODUÇÃO E DIVULGAÇÃO TOTAL OU PARCIAL DESTE TRABALHO, POR QUALQUER MEIO CONVENCIONAL OU ELETRÔNICO, PARA FINS DE ESTUDO E PESQUISA, DESDE QUE CITADA A FONTE.

Catalogação na publicação

Serviço de Biblioteca e Documentação

Instituto de Psicologia da Universidade de São Paulo

Suaide, André Luis Alarcon do Passo.

Desenvolvimento e validação de uma ferramenta computacional para mensuração das curvaturas da coluna vertebral / André Luis Alarcon do Passo Suaide; orientador Marcos Duarte. -- São Paulo, 2008.

$52 \mathrm{p}$.

Dissertação (Mestrado - Programa de Pós-Graduação em Psicologia. Área de Concentração: Neurociências e Comportamento) - Instituto de Psicologia da Universidade de São Paulo.

1. Doenças da coluna vertebral 2. Curvaturas da coluna vertebral 3. Escoliose 4. Medidas 5. Programas de computador I. Título. 


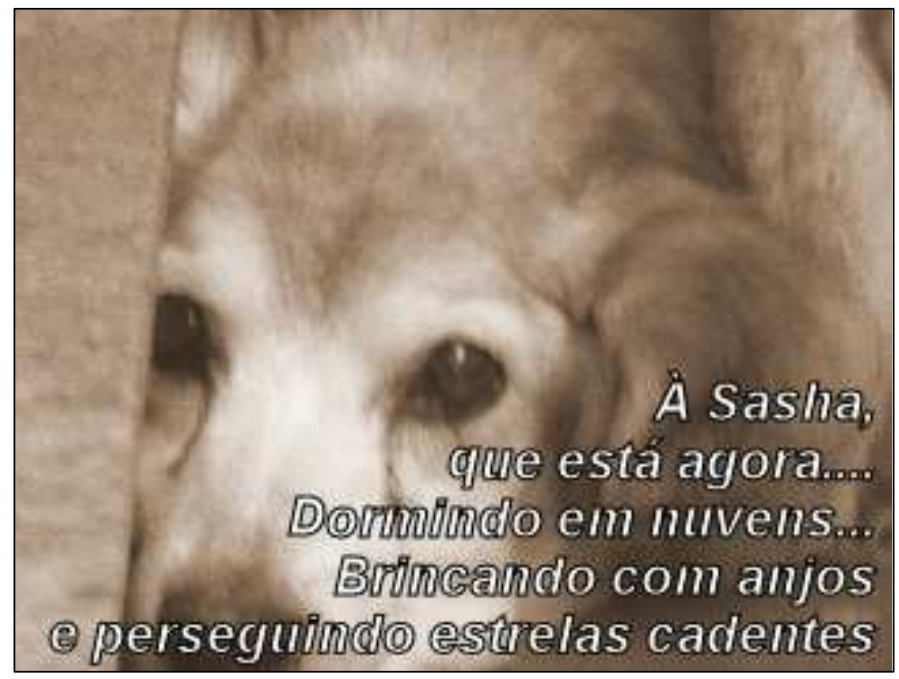




\section{AGRADECIMENTOS}

Agradeço primeiramente ao professor Dr. Marcos Duarte, que me acolheu, incentivou e guiou nesse trabalho. Esteve sempre disposto, aconselhando, ajudando e criticando do melhor jeito possível. É um exemplo para mim e a todos do laboratório e além.

Aos meus pais, Lucy e Suaide, e por mais piegas que seja, são os maiores responsáveis por tudo que acontece e acontecerá em minha vida; fontes diretas de inspiração, seres que serei eternamente grato por tudo e para sempre. Amo vocês!

Também agradeço aos meus irmãos, Beto e Alexandre, por estarem sempre ao meu lado em todos os momentos de minha vida, e espero, até o final dela. As minhas cunhadas, Luciana e Márcia, e meus sobrinhos, Lucas e Rafael - e porque não, ao terceiro que está por vir -, por serem integrantes dessa vida também, compartilhando histórias que são contadas inúmeras vezes por nossas lembranças.

À minha família, que seria uma injustiça nomeá-los aqui, pois gastaria mais de uma página, porém abro exceção aos meus tios Walter e Déa que são exemplos para mim e para todos da família.

Ao Mario, Sayoko e a toda família Ino, formada de pessoas maravilhosas e que sinto tê-la conhecido há apenas pouco mais de três anos. Obrigado por ser minha nova família.

Aos meus amigos: Tomas, Tanabe, Harumi, Diriga, Masaishi, Andrézão, Mariana, Bel, Leandro, Carlos 'Tadao' e Fábio Perdiz, que no momento certo, apareceram na minha vida e se tornaram parte importante dela.

Ao Reginaldo Fukuchi, amigo que foi o fisioterapeuta responsável pela marcação dos voluntários e que me ajudou na coleta.

Aos membros do LoB, excelentes companhias e amigos com futuros incríveis.

Aos novos, porém estimados, amigos José Corsini e Gewerton, que me ajudaram na revisão estatística.

Ao RiskOffice, empresa que acredita em mim e me deu essa oportunidade de realizar um sonho. 
Quem é essa menina que eu nunca tinha visto antes que me faz dormir em sonhos velando sua porta e gira seus olhos como mágica no tempo e me faz flutuar dançando ao seu redor.

Invadiu minha vida ditando seu rumo e a transformou num reino todo nosso e nele perco todo o medo de fechar os meus olhos pois sei que com os seus eu posso enxergar também.

E que menina é essa que completa o que sinto e sinto... e sinto... de novo... o novo... passeamos num céu infinito de mãos dadas e como se fosse pouco, passeamos novamente.

E quando temos vontade de chorar, choramos juntos criando tempestades de emoções e paixão mas no final vemos a noite tão clara como nossa felicidade que poderia muito bem tomar o lugar do sol.

Quem é essa menina que junta tudo numa só coisa que une como só ela, tristeza, alegria, solidão e multidão cantando um sonho de poucas palavras mas que em sua voz é a mais bela das canções.

É uma menina que está acima de rimas e exala ternura em uma risada tão pura agradeço por ter me escolhido como seu menino de sorte em um mar de probabilidade

Cris... te amo, ou melhor, muito mais

E por fim, agradeço à Cris, do fundo do coração, por ela ter me feito uma pessoa incrivelmente feliz aceitando em se casar comigo. 


\section{SUMÁRIO}

AGRADECIMENTOS

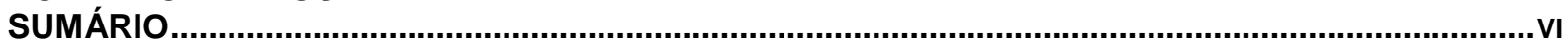

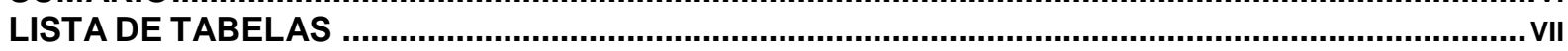

LISTA DE FIGURAS

GLOSSÁRIO

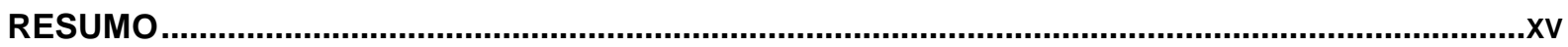

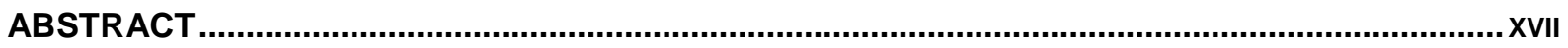

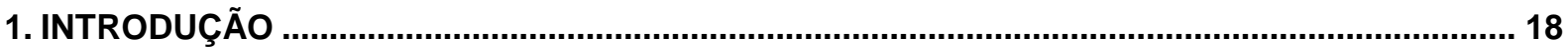

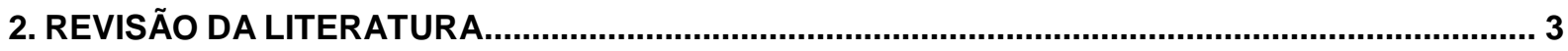

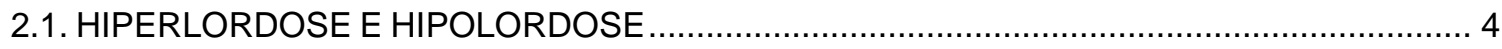

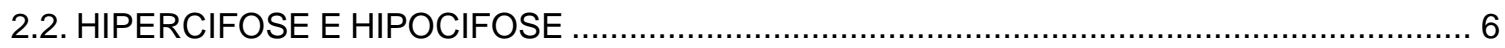

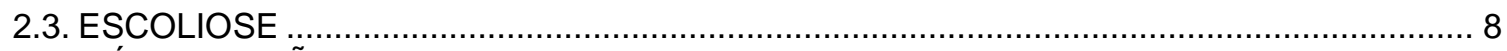

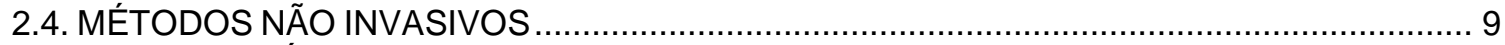

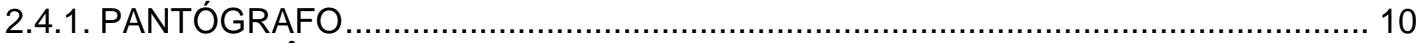

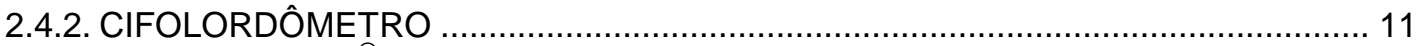

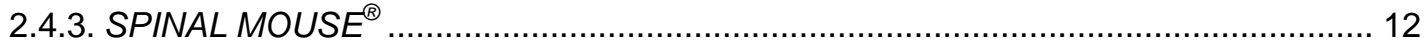

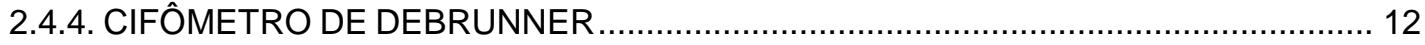

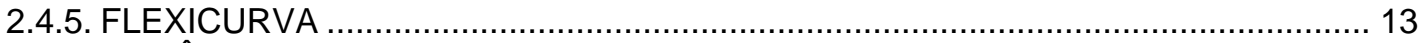

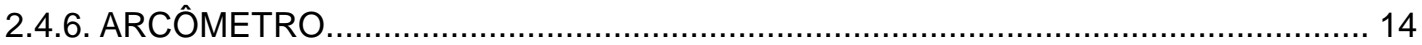

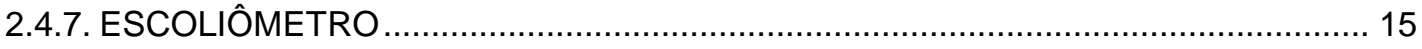

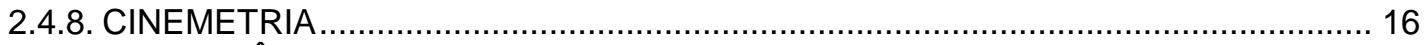

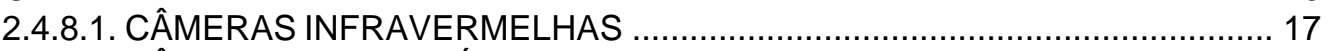

2.4.8.2. CÂMERAS FOTOGRÁFICAS …………............................................ 19

3. OBJETIVO

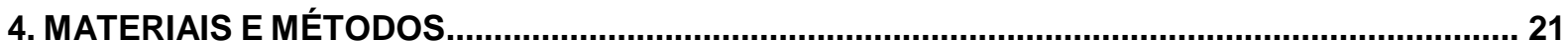

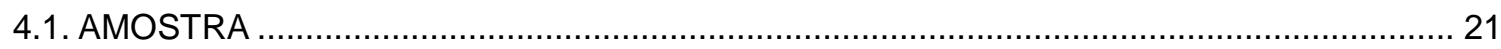

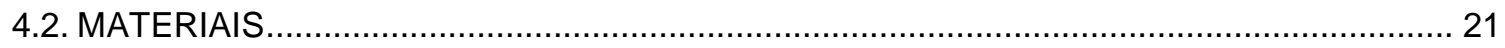

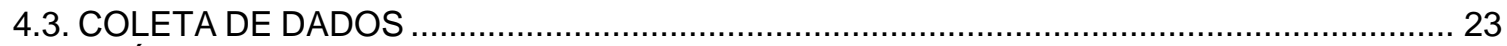

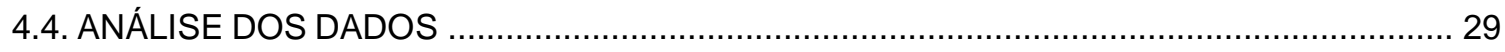

5. RESULTADOS

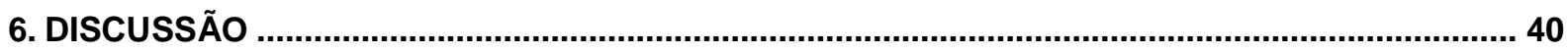

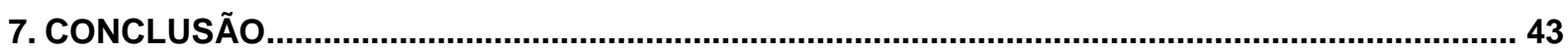

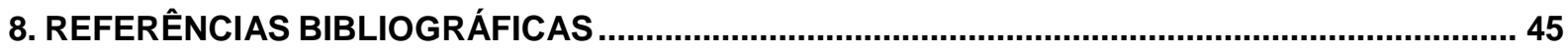

ANEXO I - TERMO DE CONSENTIMENTO LIVRE E ESCLARECIDO …..................................... 52 


\section{LISTA DE TABELAS}

TABELA 1 - COORDENADAS ENCONTRADAS POR CINEMETRIA E LOB ANALYTICS PARA UM INDIVÍDUO......... 32

TABELA 2 - ÂNGULOS DA CIFOSE TORÁCICA MEDIDOS ATRAVÉS DE C $7 \mathrm{ET}_{12}$. 33

TABELA 3 - MÉDIA, DESVIO PADRÃO E INTERVALO DOS ÂNGULOS MEDIDOS. 34

TABELA 4 - ÂNGULOS DA ESCOLIOSE MEDIDOS PELA CINEMETRIA E LOB ANALYTICS. 35

TABELA 5 - QUANTIDADE DE INDIVÍDUOS AGRUPADOS PELA DIFERENÇA ABSOLUTA ENTRE OS MÉTODOS ... 35

TABELA 6 - TOTAL DE ÂNGULOS METIDOS PELO LOB ANALYTICS EM RELAÇÃO AOS DA CINEMETRIA..... 36 


\section{LISTA DE FIGURAS}

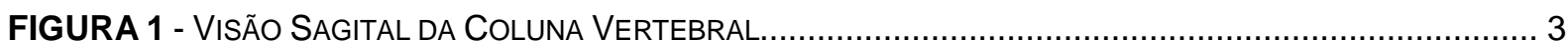

FIGURA 2 - MENSURAÇÃO DA LORDOSE PELO MÉTODO DE COBB................................................ 5

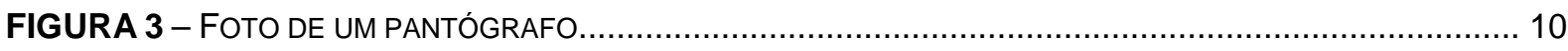

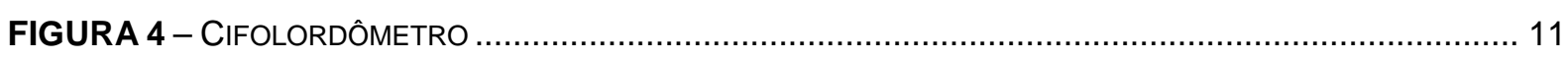

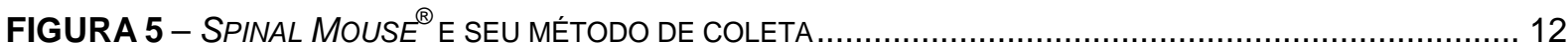

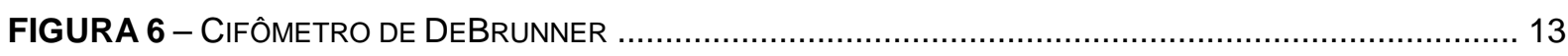

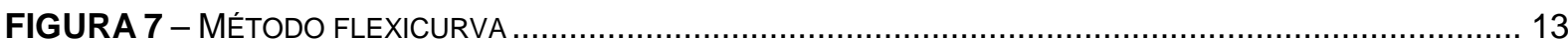

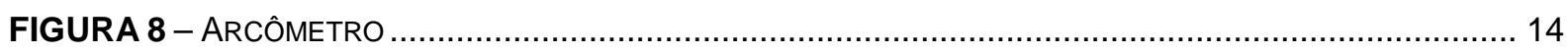

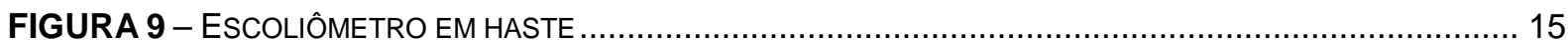

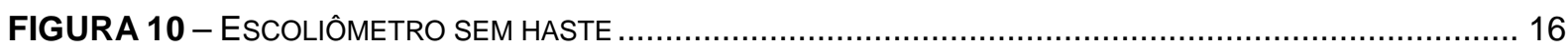

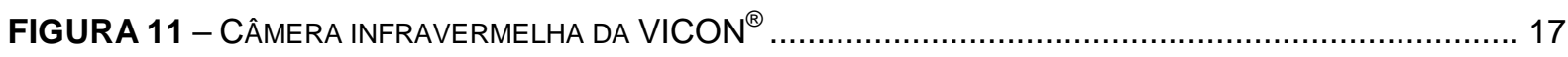

FIGURA 12 - CRONOFOTOGRAFIA DE ÉTIENNE MAREY REPRESENTANDO A CORRIDA DE UM HOMEM.......... 19

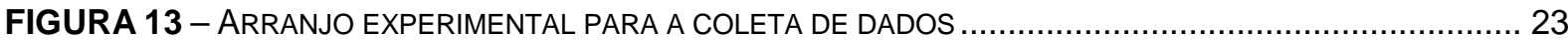

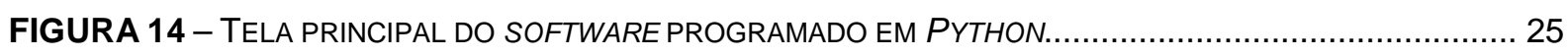

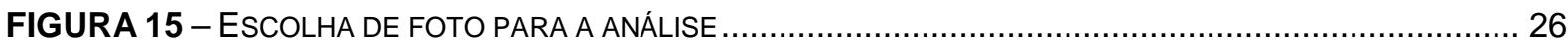

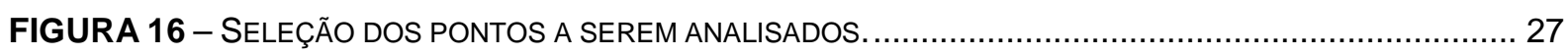

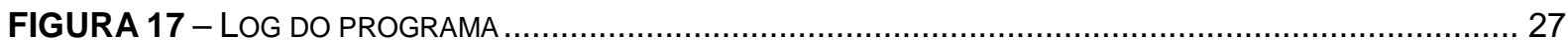

FIGURA 18 - SALVANDO OS DADOS EM DISCO

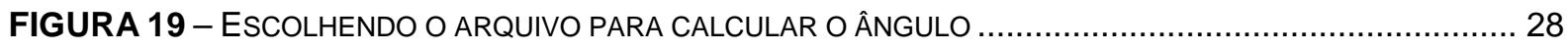

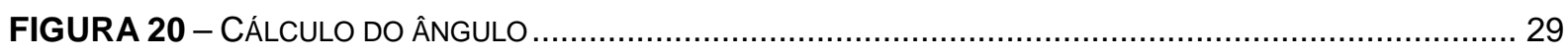

FIGURA 21 - REPRESENTAÇÃO PLANA DA CIFOSE TORÁCICA E LORDOSE LOMBAR .................................. 29

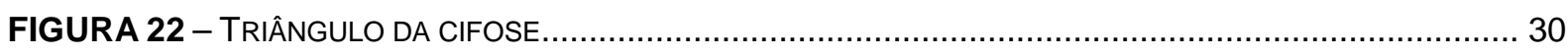

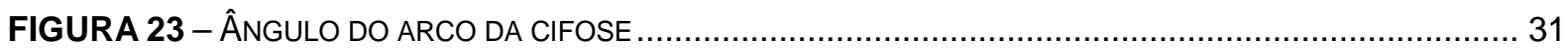

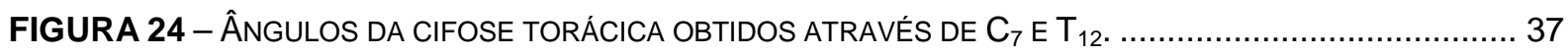

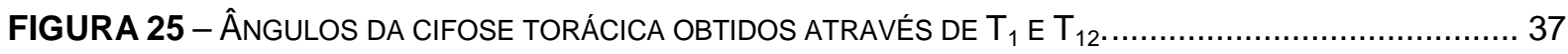

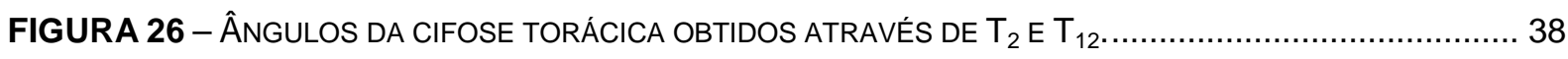

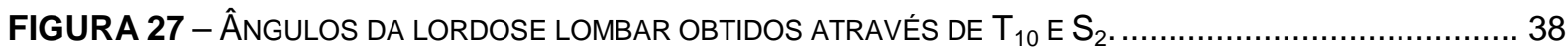

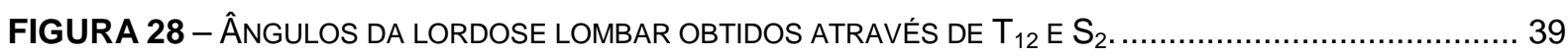


FIGURA 29 - ÂNGULOS DA ESCOLIOSE. 39

FIGURA 30 - TODOS OS ÂNGULOS CONSOLIDADOS (N=97). 40 


\section{GLOSSÁRIO}

Acurado: Real, perfeito.

Ângulo: Área entre duas semi-retas que se encontram.

Ângulo Lombossacro: Ângulo formado entre a vértebra $L_{5}$ e o Sacro.

Antropometria: Ramo das ciências biológicas que tem como objetivo o estudo dos caracteres mensuráveis do corpo humano ou suas partes.

Arcômetro: Instrumento para medição da curvatura da coluna vertebral. (Página 10)

Binomial: Ver Distribuição Binomial.

Câmeras Infravermelhas: Operam por meio do registro da luz infravermelha refletida pelos marcadores. Os sistemas que registram luz infravermelha, baseados nos marcadores, utilizam hardwares específicos que realizam operações básicas de processamento de imagens. (Página 17)

Cifolordômetro: Instrumento para medição da curvatura da coluna vertebral. (Página 11)

Cifômetro de DeBrunner: Instrumento para medição da curvatura da coluna vertebral. (Página 12)

Cifose: Curvatura da região torácica.

Cinemetria: Conjunto de métodos que nos permite a determinação da posição e orientação dos segmentos corporais, buscando medir os parâmetros cinemáticos do movimento, isto é, posição, orientação, velocidade e aceleração.

Cobb: Ver 'Método de Cobb' nesse glossário 
Coeficiente de Correlação de Pearson: Também tratado nesse estudo pela letra ' $r$ ', mede o grau da correlação entre duas variáveis. Seu valor varia ente -1 e 1 . Sendo:

$r=1 \rightarrow$ Correlação perfeita positiva entre as duas variáveis. Se uma aumenta, a outra também aumenta.

$r=-1 \rightarrow$ Correlação negativa perfeita entre as duas variáveis. Se uma aumenta, a outra diminui.

$r=0 \rightarrow$ Significa que as duas variáveis não dependem linearmente uma da outra. No entanto, pode existir uma dependência não linear.

Também pode considerar que, sendo o módulo de ' $r$ ' igual ou superior a 0.70 , há uma forte correlação; módulo de ' $r$ ' entre 0.30 e 0.7 indica correlação moderada; e módulo de 'r' entre 0 e 0.30 uma fraca correlação.

Coeficiente de Correlação Interclasse (CCl): Razão da variância entre grupos e a variância total. O ICC é usado geralmente para testar a fidedignidade entre avaliadores. Usa-se o ICC ao invés do coeficiente de correlação de Pearson quando a amostra e univariada - contém uma só variável -, e ter mais de dois grupos. O ICC é sensível à diferença entre médias e variâncias dos grupos.

Côncava: Aquela na qual qualquer segmento de reta unindo dois de seus pontos está mais próximo do observador que o trecho da curva entre esses pontos.

Convexa: Aquela na qual qualquer segmento de reta unindo dois de seus pontos está mais afastado do observador que o trecho da curva entre esses pontos.

Coronal: É o plano que divide o corpo em parte frontal (frente) e dorsal (trás).

Correlação: Indica a força e a direção do relacionamento linear entre duas variáveis aleatórias. 
Cronofotografia: É a representação de várias fases de um movimento em uma única foto. (Página 19)

Direct Linear Transformation (DLT): Métodos de reconstrução tridimensional. A partir de duas fotos e um método de calibração, pode-se transpor a imagem bidimensional das fotos para uma reprodução tridimensional.

Distribuição Binomial: Distribuição de probabilidade discreta do número de sucessos numa seqüência de ' $n$ ' tentativas tais que as tentativas são independentes; cada tentativa resulta apenas em duas possibilidades, sucesso ou fracasso. A probabilidade ' $p$ ' de cada tentativa permanece constante.

Equiprovável: Um espaço amostral finito é equiprovável quando seus eventos têm probabilidades iguais de ocorrência. Se jogarmos uma moeda, a probabilidade dela dar cara ou coroa é a mesma, $50 \%$.

Escoliose: Desvio lateral da linha mediana da coluna vertebral e devido ao alinhamento vertebral, às relações estruturais das bordas vertebrais e às articulações posteriores, a inclinação lateral é acompanhada por rotação simultânea (CAILLIET, 1979).

Extrapolação: Método matemático que permite encontrar o valor da função desconhecida em um ponto fora da zona conhecida.

Fidedígno: Que merece crédito. Confiável, verdadeiro.

Fisiologia: Estudo do funcionamento do organismo dos seres-vivos; suas múltiplas funções mecânicas, físicas e bioquímicas.

Flexicurva: Instrumento para medição da curvatura da coluna vertebral. (Página 13)

Gibosidade: É uma proeminência costal do lado convexo da curvatura escoliótica. Visuamente pode ser identificada por um 'calombo' do lado oposto à escoliose. 
Hérnia: Saliência ou projeção de um órgão ou parte dele através das paredes da cavidade que o contém normalmente.

Hipercifose: A hipercifose é o aumento da curvatura no plano sagital da região torácica.

Hiperlordose: A hipercifose é o aumento da curvatura no plano sagital da região cervical ou lombar.

Interclass correlation coefficient (ICC): Ver Coeficiente de Correlação Interclasse nesse glossário.

Intervalo de Confiança (IC): Intervalo estimado de um parâmetro estatístico. Em vez de estimar o parâmetro por um único valor, é dado um intervalo de estimativas prováveis. Quanto maior a probabilidade de o intervalo conter o parâmetro, maior será o intervalo. IC são usados para indicar a confiabilidade de uma estimativa. Um IC pode ser usado para descrever quão confiáveis são os resultados de uma pesquisa. Sendo todas as outras coisas iguais, uma pesquisa que resulte num IC pequeno é mais confiável do que uma que resulte num IC maior.

Invasivo: Agressivo. Este estudo trata invasivo aquilo que é prejudicial ao corpohumano.

Lordose: Curvatura das regiões lombar e cervical.

Método de Cobb: Desenvolvido em 1948 por J.R. Cobb, esse método utiliza a radiografia para calcular as curvaturas da coluna vertebral por meio das tangentes das vértebras.

Neoplasia: Alterações celulares que acarretam um crescimento exagerado destas células. 
Pantógrafo: Instrumento para medição da curvatura da coluna vertebral. (Página 10)

Patologia: Ciência que trata das doenças, tanto físicas quanto mentais. Comportamento patológico é aquele que foge ao normal, ao sadio e ao socialmente aceito e benéfico a todos.

Plano Sagital: É o plano que divide o corpo, em parte direita e esquerda.

Processo Espinhoso: As vértebras são os ossos que compõem a coluna vertebral dos vertebrados. A ponta de cada vértebra é conhecida como processo espinhoso. Nas vértebras cervicais o processo é proeminente, comprido e inclinado para baixo. Já nas vértebras torácicas, eles são mais compridos, ao contrário das vértebras lombares e sacrais, que são retos e curtos.

Python: Linguagem de programação. (Página 22)

Radiação: É a propagação da energia por meio de partículas ou ondas. As células quando expostas à radiação sofrem ação de fenômenos físicos, químicos e biológicos. A radiação causa ionização dos átomos, que afeta moléculas, que poderão afetar as células.

Radiografia: É a fotografia obtida através de raios- $X$

Regressão Linear: Método estatístico que utiliza a relação entre duas ou mais variáveis de tal forma que uma variável pode ser predita a partir da outra ou outras.

Spinal Mouse: Instrumento para medição da curvatura da coluna vertebral. (Página 12) 


\section{RESUMO}

\section{Desenvolvimento e validação de uma ferramenta computacional para mensuração das curvaturas da coluna vertebral}

\section{Autor: André Luis Alarcon do Passo Suaide}

\section{Orientador: Prof. Dr. Marcos Duarte}

A coluna vertebral desempenha um papel importante no dia a dia oferecendo suporte necessário à movimentação do tronco além da locomoção do ser humano, sendo o seu funcionamento diretamente relacionado com a qualidade de vida; sua disposição e articulação das vértebras proporcionam estabilidade e flexibilidade à coluna vertebral, atributos necessários para o equilíbrio do ser humano. A hipercifose torácica, hiperlordose lombar e escoliose são as patologias posturais mais comuns e podem ser diagnosticadas pela mensuração do ângulo da curvatura da coluna vertebral. Comumente a radiografia é utilizada como método para a mensuração de tais ângulos, porém, além de ser um método caro, é altamente invasivo por causa da exposição à radiação, por isso não é aconselhado praticá-lo muitas vezes, sendo o acompanhamento do tratamento difícil de ser feito. Há diversos métodos não invasivos, porém não combinam praticidade, baixo custo e análise tridimensional da curvatura, sendo eficazes em mensurar apenas a coluna no plano sagital. Por esses motivos, para o uso clínico, o profissional de saúde necessita de um método barato, confiável, prático, que atenda suas necessidades e não invasivo para a mensuração da curvatura da coluna vertebral.

O objetivo desse trabalho foi desenvolver e validar com a Cinemetria composto de cinco câmeras infravermelhas - uma ferramenta computacional ( $L O B$ Analytics) para mensurar esse ângulos, o software terá código aberto e uso gratuito. A média de todos os ângulos obtida pela Cinemetria foi de $43,4 \pm 18,5^{\circ}$ e pelo $L o B$ Analytics foi de $43,9 \pm 17,7^{\circ}$, com uma correlação muito forte de 0,98 . Foram feitas regressões lineares que confirmaram que ângulos calculados pelo $L O B$ Analytics são tão confiáveis quanto os calculados pela Cinemetria, que é um método bastante 
utilizado hoje em dia. Os grandes diferenciais do $L O B$ Analytics sobre a Cinemetria são: o seu baixo custo e a praticidade de usá-lo em laboratórios e clínicas.

Palavras-chave: 1. Doenças da coluna vertebral; 2. Curvaturas da coluna vertebral; 3. Escoliose; 4. Medidas; 5. Programa de computador 


\section{ABSTRACT \\ Development and validation of computational tool for measuring of curves of the spine}

\section{Author: André Luis Alarcon do Passo Suaide}

\section{Advisor: Prof. Dr. Marcos Duarte}

The spine has an important role day by day offering the necessary flexibility for movement of the trunk besides support and locomotion of humans and being is directly related to the quality of life. The provision and articulation of the vertebrae are responsible for the stability and flexibility of spine attributes necessary for the balance. The thoracic hiper and hypo kyphosis, lumbar hiper and hypo lordosis and scoliosis are the most common postural pathologies and can be diagnosed by measuring the angle of the curvature of the spine. The radiographic method has been the most popular method for such measurement, however, it is an expensive method and also invasive (because its exposure to radiation), it is not the method more indicated to be used repeatedly, being the monitoring of treatment difficult to be done. There are several noninvasive methods but they do not combine practicality, low cost and three-dimensional analysis of the spine curvature, and they are effective in measuring the spine only in the sagittal plane. For these reasons, the health professional needs a method that has low cost, reliable, practical and noninvasive methods for measurement of the curvature of the spine. The goal of this work was develop and validate, with motion capture system (Cinemetria), a computational tool for this measurement (LoB Analytics), which will be free and open source. The mean of all Cinemetria angles was $43,9 \pm 18,5^{\circ}$ and LoB Analytics angles was $43,9 \pm 17,7$, with a very strong correlation coefficient of 0,98 . Linear regressions confirmed that LoB Analytics angles are as reliable as those calculated by Cinemetria, which is a method widely used today. The differentials of LoB Analytics on Cinemetria are: low cost and practicality of using it in laboratories and clinics.

Keywords: 1. Diseases of the spine; 2. Curves of spine, 3. Scoliosis, 4. Measures; 5. Computational Tool. 


\section{INTRODUÇÃO}

As doenças relacionadas à coluna vertebral vêm aumentando no mundo civilizado em decorrência de vários fatores, dentre eles, mudanças importantes no comportamento, como sedentarismo e maus hábitos posturais.

A coluna, além de sustentação, oferece a flexibilidade necessária à movimentação do tronco, possuindo um papel importante na postura, locomoção e equilíbrio. $O$ seu eixo ósseo ainda serve como proteção à medula espinhal e raízes nervosas (CAMPBELL-KYUREGHYAN et. al., 2005). Ela é responsável pela interligação mecânica entre os segmentos e quase todos os movimentos executados no dia a dia envolvem uma coordenação sinérgica entre os membros da coluna. Dessa forma, o funcionamento da coluna é diretamente relacionado com a qualidade de vida (CAMPOS, 2005).

As vértebras são conectadas entre si pelas articulações posteriores entre os corpos vertebrais e os arcos neurais. Elas se articulam de modo a conferir estabilidade e flexibilidade à coluna, atributos necessários para o equilíbrio. A deformidade dessa estrutura pode ser um obstáculo para a estabilidade do controle postural, já que pode interferir diretamente no centro de massa do corpo humano. Esta questão tem sido pouco investigada, pois há poucas ferramentas acuradas e acessíveis aos pesquisadores e profissionais de saúde.

Por esses pontos relatados, é de suma importância a avaliação da curvatura da coluna na medida em que tratamentos de correção, ou mesmo cirurgias, são indicadas embasadas na sua progressão.

Atualmente, a radiografia é o método mais utilizado para a avaliação da coluna vertebral, porém por muitas vezes o paciente é submetido a mais de uma sessão, o que o torna nocivo à saúde (MEDEIROS \& DAROS, 1997; FERREIRA, 1999).

$O$ efeito da radiação pode prejudicar 0 desenvolvimento sexual e 0 desenvolvimento ósseo de crianças além de aumentar o risco de neoplasias, 
principalmente em mulheres, durante a fase de crescimento. (DUTKOWSKY et. al.; 1990). Também é fortemente não aconselhável a exposição de radiação para mulheres grávidas (CAMPBELL-KYUREGHYAN et. al., 2005).

Esse método é considerado o padrão ouro para a mensuração da curvatura da coluna vertebral, porém, o seu uso, requer técnicos licenciados para sua implementação, além de ter um custo financeiro elevado (CAMPBELLKYUREGHYAN et. al., 2005).

Por causa do custo alto e de ser um método invasivo, a busca por outros métodos mais baratos e não invasivos sempre são importantes.

Os métodos não invasivos possibilitam o acompanhamento do tratamento sem se preocupar em prejudicar a saúde do paciente. Não há desgaste e o método pode ser refeito quantas vezes forem necessárias (VOUTSINAS \& MacEWEN, 1986; FERREIRA, 1999).

Há diversos métodos não invasivos atualmente, porém a maioria se prende a mensuração da curvatura da coluna vertebral no meio sagital por apenas conseguir avaliar o aspecto bidimensional da coluna vertebral.

A cinemetria é um conjunto de métodos que nos permite a determinação da posição e orientação dos segmentos corporais, buscando medir os parâmetros cinemáticos do movimento, isto é, posição, orientação, velocidade e aceleração. Um método que demonstra forte correlação com a radiografia se utiliza de câmeras infravermelhas para mensurar a curvatura da coluna vertebral (CHEN et. al., 1997; LEROUX et. al., 2000; NORMAND et. al., 2002; DESCARREAUX et. al., 2003), porém o método é economicamente inviável para se implantar em clínicas e consultórios de fisioterapia, já que o custo de implementação de um sistema ultrapassa o milhar de dólares.

A necessidade de desenvolver um método que seja acurado, acessível, fácil de usar e capaz de ser implantado em consultórios motivou esse trabalho. 
No decorrer desse trabalho uma revisão de literatura é descrita visando a melhor compreensão do cenário abordado e após os objetivos, assim como os métodos e materiais, além da análise dos dados e por fim as discussões e conclusões.

\section{REVISÃO DA LITERATURA}

Em geral, a coluna vertebral humana (Figura 1) se compõe de trinta e três vértebras sendo elas sete cervicais, doze torácicas, cinco lombares, cinco sacrais e quatro coccígeas que são ligadas por discos invertebrais. As curvas, torácica e sacral, são convexas posteriormente e as curvaturas cervical e lombar são convexas anteriormente (PANJAB \& WHITE, 1980).

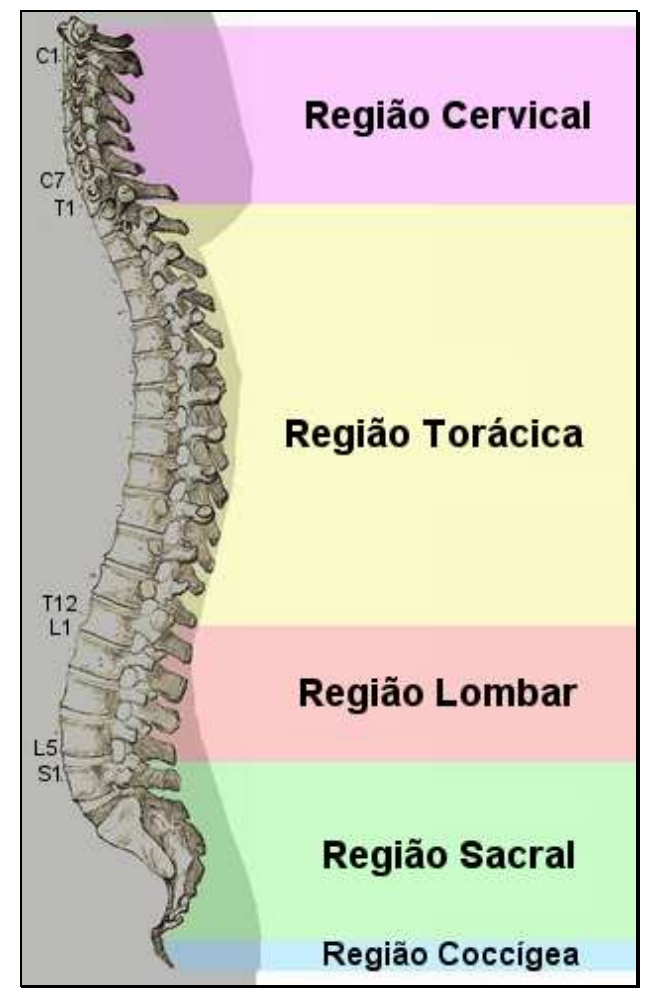

Figura 1 - Visão Sagital da Coluna Vertebral

A curvatura da região torácica é chamada de cifose torácica. A curvatura abaixo, a da região lombar, é chamada de lordose lombar. Também na parte superior da coluna, na região cervical, a curvatura denomina-se lordose cervical. 
Algumas das patologias mais comuns são a hipercifose e hipocifose torácica, hiperlordose e hipolordose lombar e a escoliose.

\subsection{HIPERLORDOSE E HIPOLORDOSE}

Hiperlordose é o termo utilizado para determinar o aumento da curvatura anterior (cervical e lombar) fisiológica (STAGNARA et. al., 1982). Hipolordose seria o contrário, a diminuição dessa curvatura - uma aparência mais reta.

A região lombar desempenha um papel de suma importância para a posição ereta visto que assiste a manutenção da postura vertical. A pélvis é a área mais estável do corpo e funciona como um amortecedor durante a passada. A curvatura lombar se equilibra sobre a pélvis e tem a capacidade de variar sua inclinação em relação à pélvis. Um aumento no ângulo lombossacro determina que a curvatura lombar seja aumentada, a fim de promover o equilíbrio do corpo (GELB et. al., 1995; EVCIK \& YUCEL, 2003; VIALLE et. al., 2005).

Foi verificado que alterações na lordose lombar influenciam vários aspectos da mecânica da coluna podendo causar danos aos tecidos adjacentes. A flexão além do fisiológico da coluna lombar, comparada com a postura normal, resulta em redução de força dos músculos extensores, aumenta o risco de lesões nos ligamento e herniação posterior do disco e diminuição da tolerância de esforços físicos - como o carregamento de peso (McGILL, HUGHSON \& PARKS, 2000).

O procedimento mais comum para a mensuração da lordose, cifose e escoliose é o método de Cobb. Desenvolvido em 1948, esse método utiliza a radiografia para calcular as curvaturas da coluna vertebral por meio das tangentes das vértebras.

Há vários parâmetros diferentes para mensurar o ângulo da lordose. Alguns autores, embasados no método de Cobb, traçaram uma linha perpendicular a $T_{12} e$ outra perpendicular $a S_{1}$ e na intersecção dessas linhas se tem o ângulo de Cobb 
(Figura 2) (PROPST-PROCTOR \& BLECK, 1983; VOUTSINAS \& MACEWEN, 1986; BERNHARDT \& BRIDWELL, 1989; GELB et. al., 1995; VEDANTAM et. al., 1998).

O método de Cobb apenas reflete o estado das duas vértebras descartando as mudanças dentro do arco analisado. Sabe-se que é mais acurado utilizar o comprimento e o arqueamento da coluna para descrever a curvatura da (BERNHARDT \& BRIDWELL, 1989).

Independente de suas limitações, esse método é en considerado o padrão-ouro ${ }_{2}^{1}$ sendo referência para estudos que visam validar instrumentos não invasivos de medição da curvatura da coluna vertebral (KYUREGHYAN et. al., 2005), apresentando boa reprodutibilidade intra e inter avaliadores com um erro médio de $\underline{2 \pm 1 ㅇ}$ (BERNHARDT \& BRIDWELL, 1989).

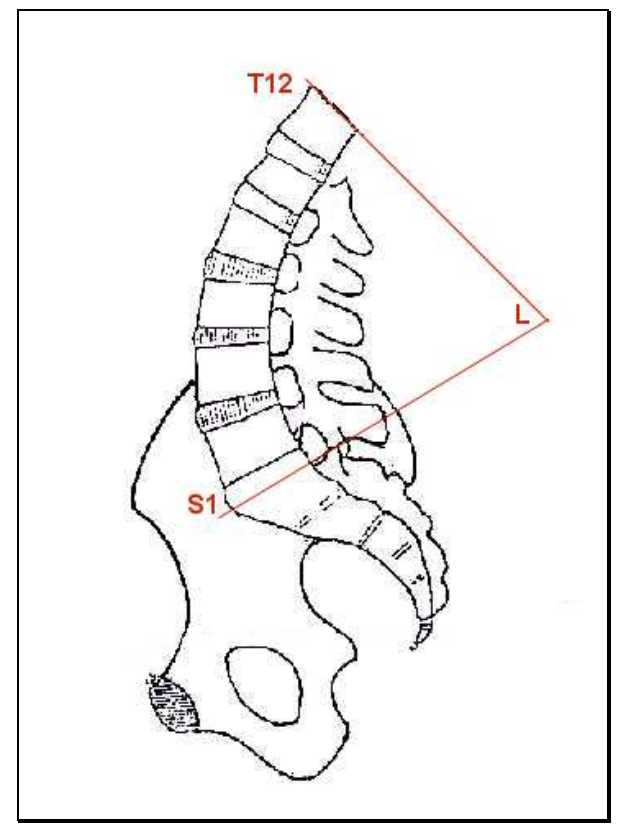

Figura 2 - Mensuração da lordose pelo método de Cobb

\footnotetext{
${ }^{1} \mathrm{~A}$ radiografia trata de retornar fidedignamente a estrutura e coordenadas de cada ponto no espaço, sendo uma representação precisa do real. O Método de Cobb utiliza esses dados para chegar ao ângulo da curvatura. Ambos são tratados como padrão-ouro para suas devidas finalidades. Quando utilizados juntos, é considerado o padrão-ouro para avaliar e mensurar a curvatura da coluna vertebral.
} 
Não há padrão para a forma exata da coluna lombar em repouso, variando de indivíduo para indivíduo, dificultando assim a definição do que pode ser chamado de curvatura lombar normal (BOGDUK, 1997; VIALLE et. al., 2005).

Bradford et. al. (1994), utilizando a vértebra $L_{1}$ e o sacro, encontrou um intervalo de $33^{\circ}$ a $79^{\circ}$ para ângulos normais da lordose lombar, e de $18^{\circ}$ a $69^{\circ}$ quando utilizado $L_{1}$ a $L_{5}$ para a mensuração. Já Propst-Proctor e Bleck (1983) fixam os valores entre $22^{\circ}$ e $54^{\circ}$ e Bernhardt e Bridwell (1989) colocam entre $14^{\circ}$ e $69^{\circ}$, com média em 44ํㅡㄹ para os ângulos normais. Leroux et. al. encontrou $52^{\circ}$ de curvatura normal lombar. Por fim, Vialle et. al., utilizando radiografias digitalizadas encontraram $60^{\circ}$ de curvatura.

Roussouly et. al. (2005), disseram que o perfil sagital da coluna é geralmente caracterizado como sendo cifose de $T_{1}$ a $T_{12}$ e lordose entre $L_{1}$ e $L_{5}$. $E$ ainda observam que as diferenças entre as curvas normais e patológicas são mais claras no alinhamento coronal do que no sagital.

Como visto, há uma discrepância de valores na mensuração da lordose. Fernand e Fox (1985), Jackson e McManus (1994) e Harrison et. al. (2001), justificam falando que há uma carência de estudos que avaliam o ângulo normal da curvatura lombar e que apesar de muitos usarem o método de Cobb, não há definição e consenso nos parâmetros utilizados para mensurar o ângulo.

\subsection{HIPERCIFOSE E HIPOCIFOSE}

A hipercifose é o aumento da curvatura no plano sagital da região torácica. Em contrapartida, a hipocifose é a diminuição dessa curvatura. Essas deformidades promovem alterações anatômicas ocasionando uma curvatura diferenciada do dorso. As causas mais comuns da hipocifose e hipercifose são as danificações vertebrais seguidas de uma fratura, de um episódio infeccioso ou de má formação congênita. Problemas mecânicos surgem causados pela diferente configuração das vértebras no plano sagital. O tratamento - muitas vezes cirurgicamente - se torna essencial para evitar problemas mais graves (SAR \& ERALP, 2002). 
O desvio postural não se torna um problema meramente estético. Essas falhas podem acarretar dor e incapacidade física. (KENDALL, MCCREARY \& PROVANCE, 1995).

As mudanças posturais são diretamente relacionadas com o aumento do risco das lesões ortopédicas, causando um mau alinhamento das estruturas ósseas e articulares, provocando sobrecarga em determinadas articulações, diminuindo assim a eficiência muscular e ligamentar (RIBEIRO et. al., 2003).

Similarmente ao método usado para encontrar a curvatura da lordose (Figura 2), é mensurado o ângulo da cifose, porém os parâmetros usados são outros. Bradford et. al. (1994) utilizaram as vértebras $T_{1}$ e $T_{12}$ para a o cálculo do ângulo da cifose. Já Teixeira (2006) utilizou-se das vértebras $C_{7}$ e $T_{12}$ enquanto Leroux et. al. (2000) usou $T_{2}$ e $T_{12}$.

O tratamento da hipercifose está vinculado ao ângulo da curvatura da cifose. Aparecimento de dores lombares é mais comuns para pessoas com hipercifose, além de propiciar certa timidez com sua aparência física ou mesmo problemas cardiorespiratórios (POOLMAN, BEEN \& UBAGS, 2002).

Alguns autores, concluíram que o ângulo normal da cifose torácica varia entre $20^{\circ}$ e $40^{\circ}$ (POOLMAN, BEEN \& UBAGS, 2002). Loubresse, Vialle \& Wollf (2005) citam que o ângulo médio da cifose torácica é $37^{\circ}$, porém, outros estipularam que 0 limite entre fisiológico e patológico é o intervalo de $20^{\circ}$ a $60^{\circ}$ (FON, PITT \& THIES, 1980); (BERNHARDT \& BRIDWELL, 1989).

No caso da cifose torácica, os valores normais são bem definidos, algo que não ocorre para a lordose lombar (BERNHARDT \& BRIDWELL, 1989). Mais estudos para a lordose e uma melhor definição são importantes. 


\subsection{ESCOLIOSE}

A escoliose trata-se de um desvio lateral da linha mediana da coluna vertebral e devido ao alinhamento vertebral, às relações estruturais das bordas vertebrais e às articulações posteriores, a inclinação lateral é acompanhada por rotação simultânea (CAILLIET, 1979; SCHROTH, 1992).

A distribuição das forças na concavidade é alterada pelas curvaturas patológicas e podem chegar a deformar o quadro cartilaginoso das vértebras em pessoas muito jovens e, por conseguinte, mais adiante, as próprias vértebras. $\mathrm{O}$ núcleo é deslocado até a convexidade, quando se reúnem as condições para sua progressão. Estas pressões excessivas determinam uma série de modificações bioquímicas e histológicas que conduzem, no adulto, à degeneração discal e à osteoartrose no lado côncavo. Contrariamente, a ausência de pressão sobre a convexidade favorece seu menor conteúdo mineral ósseo (BIOT et. al, 2002).

A sua origem pode ser causada por uma paralisia, ou por doenças genéticas ou hereditárias ou de outras causas identificáveis. Cerca de $80 \%$ dos casos são idiopáticas. (SCHROTH, 1992).

A presença da escoliose pode desencadear vários problemas como uma melhor ventilação pulmonar no lado da gibosidade e uma menor ventilação do lado contrário. Além disso, a mudança do centro de gravidade causa um desequilíbrio no indivíduo (SCHROTH, 1992).

Apesar do mesmo princípio ser usado para a mensuração da escoliose, os parâmetros não podem ser definidos, ficando a análise a critério de cada caso. Normalmente são usadas as vértebras que inclinam ao máximo para dentro da concavidade da curva estrutural (LIMA, 2002). Tendo as vértebras definidas, o processo é igual ao descrito acima para lordose e cifose.

Presume-se que a escoliose, assim como as demais deformidades tratadas anteriormente, seja causada pela fraqueza ou ausência de estruturas anatômicas no 
lado convexo da curva ou por uma forte atividade de seus antagonistas no lado côncavo. (BRADFORD et. al., 1994).

Ricard (1999) classificou a ocorrência da escoliose em quatro graus, mensurada por intervalo de ângulos:

- Grau 1: angulação inferior a 20ำ - não há necessidade de tratamento fisioterapêutico;

- Grau 2: angulação de $20^{\circ}$ a $30^{\circ}$ - necessidade de tratamento fisioterapêutico;

- Grau 3: angulação de 31 a 50ํ- tratamento fisioterapêutico e uso de colete;

- Grau 4: angulação superior a 50ํ- tratamento cirúrgico.

\subsection{MÉTODOS NÃO INVASIVOS}

Atualmente é mais comum o uso da radiografia para a mensuração da curvatura da coluna vertebral - validado cientificamente -, porém a exposição à radiação é algo maléfico à saúde, tendo em vista ainda que na maioria dos casos, o paciente está sujeito a mais de uma sessão. Freqüentes doses de radiação podem danificar o crescimento ósseo e o desenvolvimento sexual de crianças (DUTKOWSKY et. al., 1990; MEDEIROS \& DAROS, 1997).

Além de requerer uma pessoa especializada e licenciada para manipular o exame, esse método é caro e impróprio para usar apenas para mensuração. Lembra-se também que não é aconselhável para grávidas se exporem à radiação. Por causa desses pontos, outros métodos foram criados para mensurar as curvaturas da coluna a fim de facilitar, baratear, e acima de tudo, não por em risco a saúde dos pacientes (CAMPBELL-KYUREGHYAN et. al., 2005). 
Pelo fato de serem não invasivos, os métodos propiciam o acompanhamento e evolução do paciente não se preocupando no número de vezes que será feita a coleta de dados (VOUTSINAS \& MacEWEN, 1986; FERREIRA, 1999).

\subsubsection{PANTÓGRAFO}

O pantógrafo ${ }^{2}$, inventado em 1603 pelo astrônomo alemão Christoph Scheiner, é um aparelho utilizado para fazer ampliações e reduções de figuras ou formas geométricas. É constituído por quatro barras articuladas e fixadas entre si, sendo duas maiores e duas menores (Figura 3).

Para o uso fisioterapêutico, uma superfície de desenho é fixada sob 0 pantógrafo para representar, em desenho, o contorno da linha do tronco. Os pacientes ficam imóveis, em pé, e os processos espinhosos que servirão de parâmetros para a mensuração do ângulo da curvatura são definidos. Na extremidade, que passará na coluna do paciente, há uma rodinha. Conforme a roda desliza na curvatura essa é desenhada na superfície de desenho, tendo assim, a cifose e lordose (WILNER, 1981).

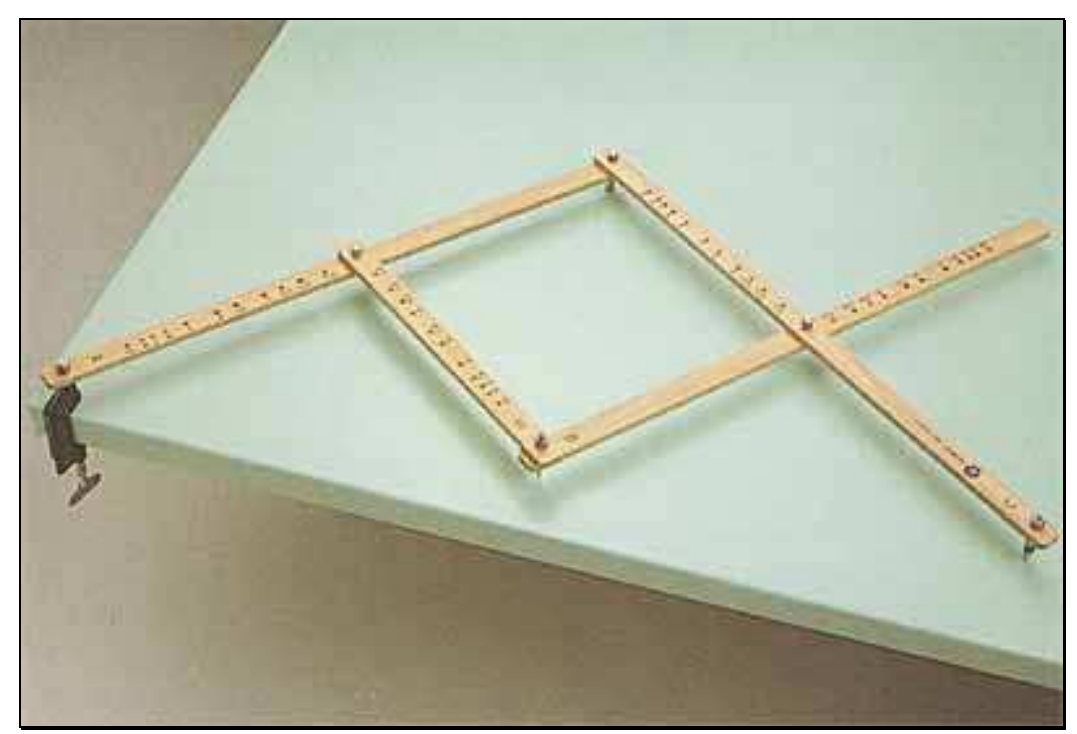

Figura 3 - Foto de um pantógrafo

\footnotetext{
${ }^{2}$ Do grego pantos (tudo) + graphein (escrever)
} 
A partir do contorno da coluna é encontrado o ângulo da cifose e da lordose por meio de análise geométrica. Há uma forte correlação entre a pantografia e o raios- $X(r=0,97)$ (WILNER, 1981).

Apesar de ser de fácil manuseio, o pantógrafo não consegue indicar se o paciente tem escoliose por criar um desenho plano e a escoliose é uma deformidade tridimensional.

\subsubsection{CIFOLORDÔMETRO}

O cifolordômetro (Figura 4) foi adaptado por Baraúna em 1999 e sua configuração conta com uma haste vertical de alumínio de 39 x $58 \mathrm{~mm}$ e 1,97 cm de altura além de contar com 39 hastes horizontais com secção transversa de um quarto de polegada e $40 \mathrm{~cm}$ de comprimento, que são móveis, indeformáveis e eqüidistantes por quatro centímetros uma da outra. O aparato está fixado sobre uma plataforma de apoio ortostático com área de 73 x $56 \mathrm{~cm}$ em um piso de borracha, antiderrapante. $O$ desenho que representa a forma da coluna vertebral no plano sagital é representado em uma folha de papel, fixada atrás do cifolordômetro (BUSTAMANTE, 2002; BARAÚNA, 2005).

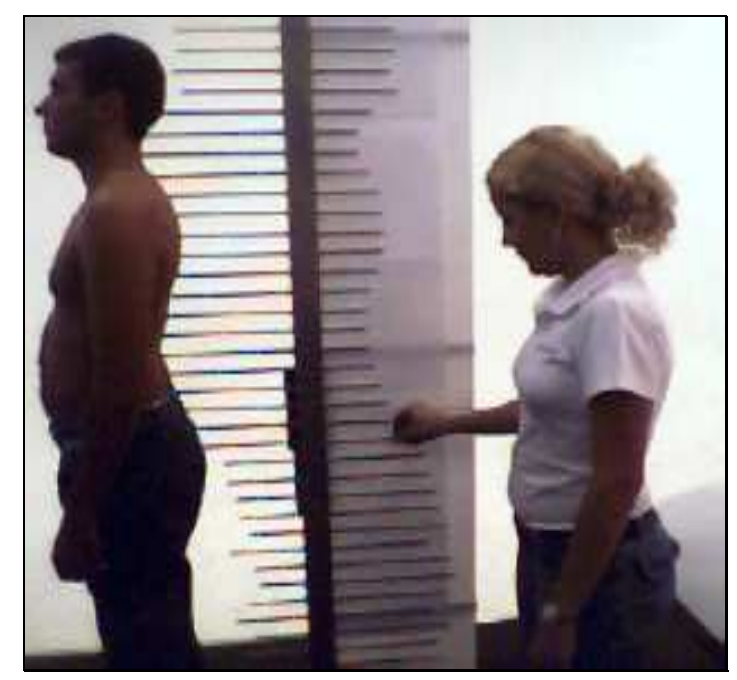

Figura 4 - Cifolordômetro

Fonte: Laboratório de Avaliação do Movimento Humano (UNITRI) 
O método mostrou-se confiável intra e inter observador para a avaliação da curvatura lombar, com um coeficiente de correlação forte $(r=0,89)$, sendo possível à mensuração quantitativamente da curvatura através da radiografia e da cifolordômetria (SOUZA, 2006).

Porém, assim como o pantógrafo, o método não consegue mensurar a escoliose por não representar a coluna em três dimensões.

\subsubsection{SPINAL MOUSE ${ }^{\circledR}$}

O aparelho (Figura 5) é formado por uma carcaça curva e duas rodas que mensura as mudanças de inclinação e suas distâncias através de um prumo interno. O aparelho se comunica via wireless com a base, que não deve ficar a mais de 2 metros do spinal mouse ${ }^{\circledR}$. Mannion et. al. (2004) realizaram um estudo e por fim conseguiram um ICC de 0,83 entre os dois examinadores que participaram, obtendo ICC menores variando os dias de coletas.

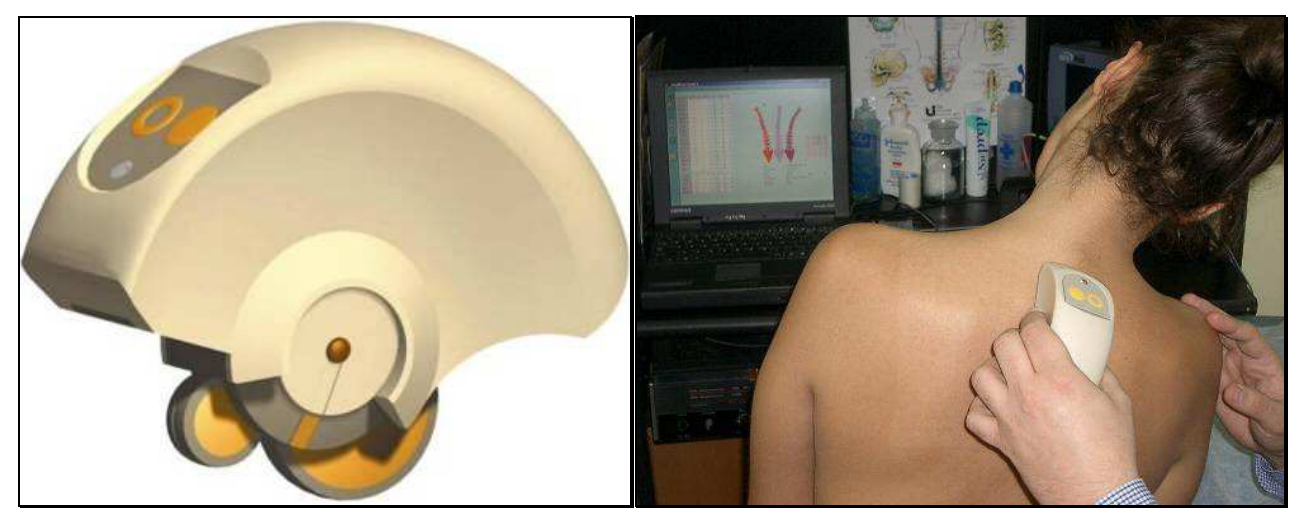

Figura 5 - Spinal Mouse ${ }^{\circledR}$ e seu método de coleta

O preço inicial do Spinal Mouse é próximo aos oito mil dólares.

\subsubsection{CIFÔMETRO DE DEBRUNNER}

O cifômetro de DeBrunner (Figura 6) é um aparelho simples, porém de manuseio um tanto quanto difícil por ser pesado e, um bom modelo, caro. Para mensurar o ângulo colocam-se as bases nos processos espinhosos que deseja analisar. Lundon, Li \& Biberstein (1998) compararam o método de Cobb por 
radiografia com o cifômetro e acharam uma boa correlação entre eles. Korovesis et. al. (2001) encontraram um ICC de 0.84 entre os dois métodos.

Assim como os métodos mostrados anteriormente, o Cifômetro de DeBrunner se limita a trabalhar apenas com o plano sagital, não sendo possível a mensuração da escoliose.

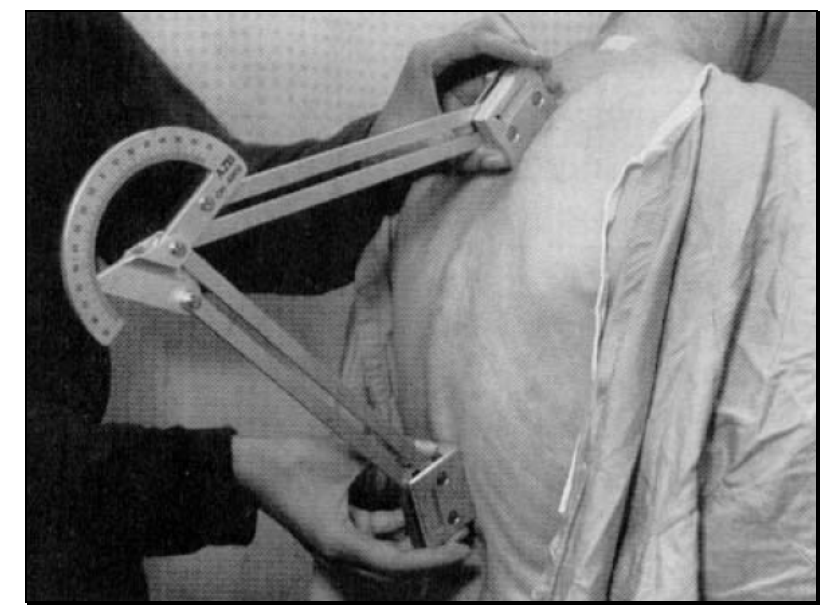

Figura 6 - Cifômetro de DeBrunner

Fonte: Lundon, Li \& Bibershtein, 1998

\subsubsection{FLEXICURVA}

É uma régua flexível de chumbo (Figura 7), de baixo custo, que por ser flexível, é moldável. Com o paciente em pé, posiciona-se a régua o mais próximo da linha média da coluna entre os processos espinhosos de $\mathrm{C}_{7}$ e $\mathrm{S}_{1}$.

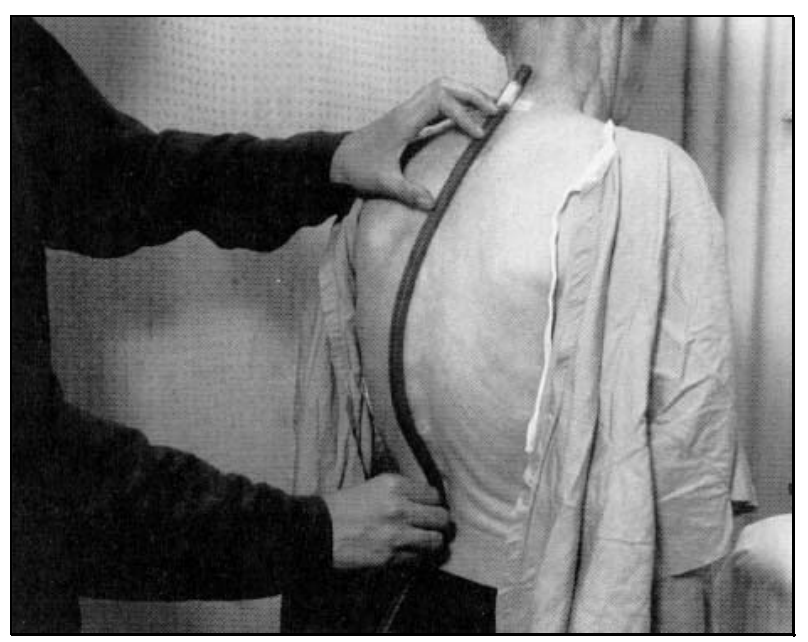

Figura 7 - Método flexicurva

Fonte: Lundon, Li \& Bibershtein, 1998 
Moldando a régua conforme a geometria da coluna vertebral do paciente, a régua é sobreposta em um pedaço de papel onde seu contorno é traçado. Une-se o começo e o final da curva por uma reta. Por meio de análise geométrica acha-se o ângulo de curvatura (TEIXEIRA, 2006).

Em estudo, Lundon, Li \& Biberrshtein (1998) verificaram que a média dos ângulos medidos com esse método e com 0 cifômetro de DeBrunner diferia em

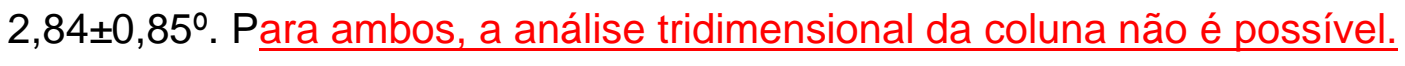

\subsubsection{ARCÔMETRO}

Assim como outros métodos, o arcômetro (Figura 8) serve para mensurar apenas o ângulo da cifose e lordose. Formado por uma régua com três hastes perpendiculares, sendo uma fixa - a primeira - e as outras duas, móveis. Posiciona a primeira haste no processo espinhoso que se refere ao começo da curvatura, a terceira haste no final da curvatura e a haste do meio no processo espinhal mais aberto da curvatura. As medidas obtidas em $\mathrm{mm}$ podem ser convertidas para ângulo por meio de uma tabela de referência existente (D'OSUALDO, SCHERANO \& IANNIS, 1997).

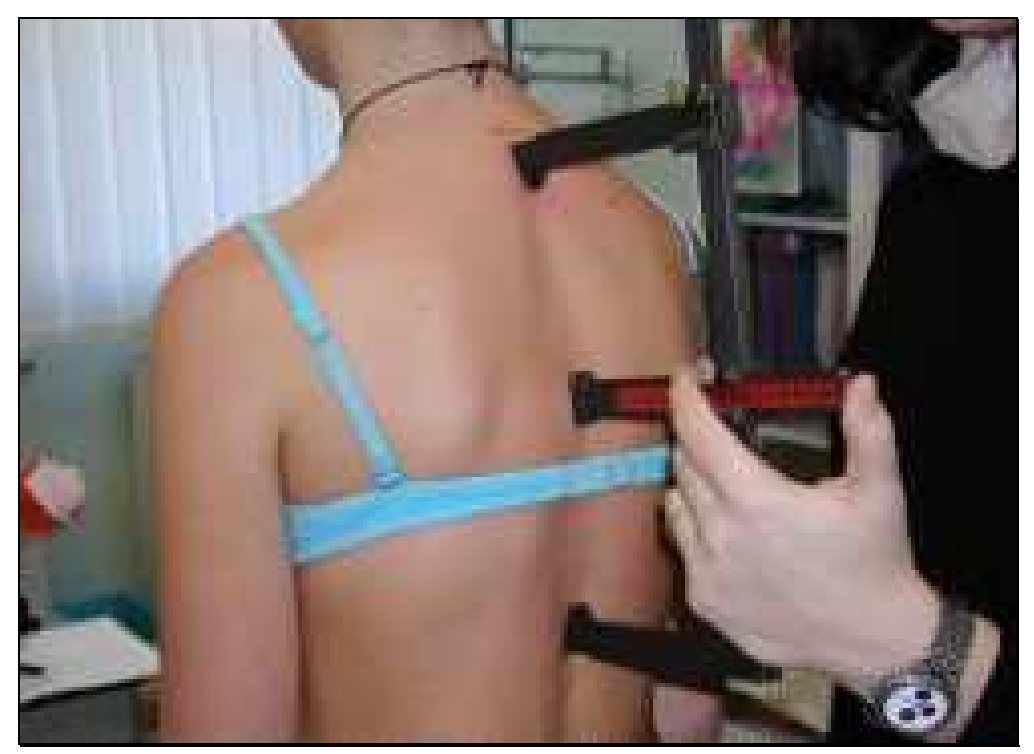

Figura 8 - Arcômetro

Fonte: D'OSUALDO, SCHERANO \& IANNIS, 1997 


\subsubsection{ESCOLIÔMETRO}

O escoliômetro é uma ferramenta usada para a medição da escoliose. O seu mecanismo principal é bastante simples: um nivelador.

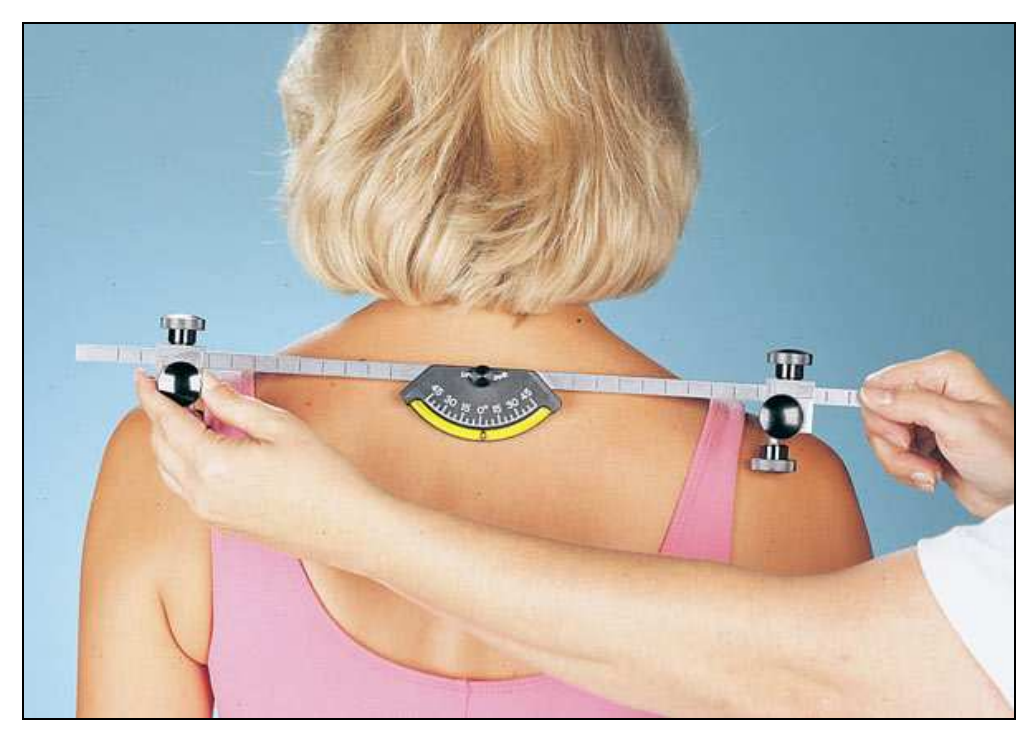

Figura 9 - Escoliômetro em haste

Há alguns tipos de escoliômetros. Um dos dois mais utilizados consiste em uma haste onde há dois apoios nas suas extremidades e no centro um nivelador (Figura 9). O avaliador fixa os apoios nos pontos esquerdo e direito simétrico das costas do sujeito e o nivelador informa o ângulo de desvio.

Outro escoliômetro bastante utilizado é praticamente um nivelador com uma fenda no centro (Figura 10). O sujeito deve se curvar e o avaliador encaixa a fenda na coluna do sujeito. O nivelador mostrará o ângulo do desvio.

Bunnell (1984) realizou um estudo com 1065 sujeitos encontrando uma forte correlação com o método de Cobb pelo raio-X $(r=0,89)$, entretanto, Pearsall (1992) criticou o escoliômetro pelo alto número de falso-positivos encontrados, mostrando uma tendência em retornar um ângulo maior que o medido pelo raio-X. 


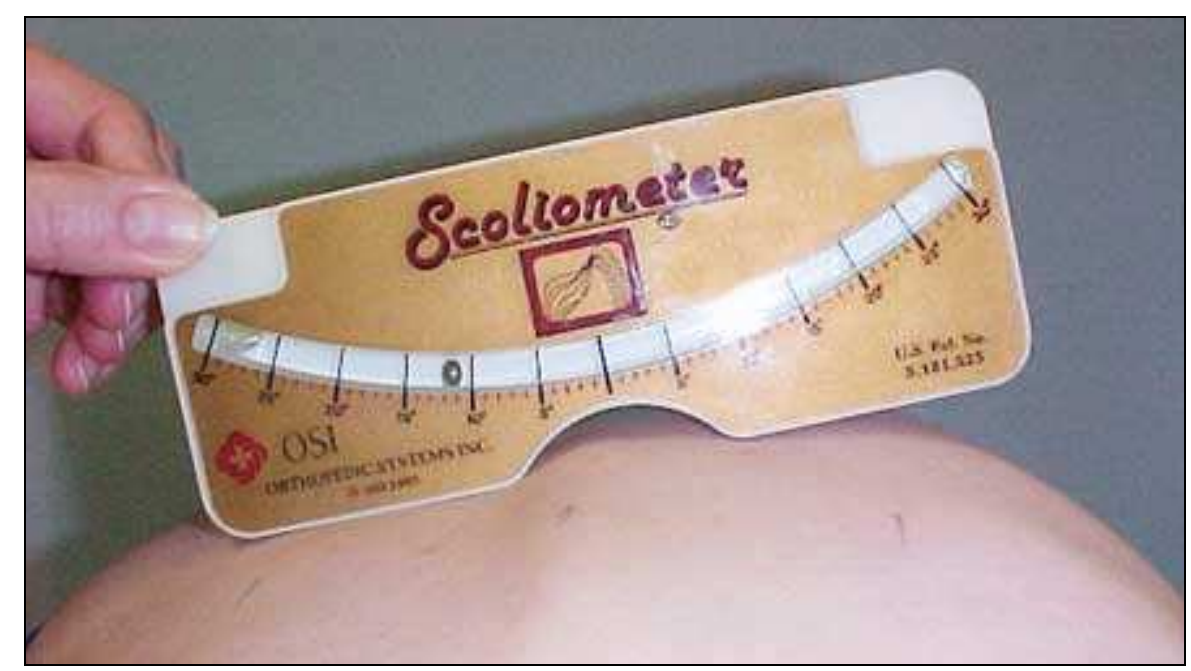

Figura 10 - Escoliômetro sem haste

Ao contrário dos demais métodos mostrados nessa revisão, o escoliômetro é específico para a mensuração da escoliose, não sendo possível a análise no plano sagital.

\subsubsection{CINEMETRIA}

A Cinemetria é a metodologia biomecânica que se destina à obtenção de variáveis cinemáticas para a descrição de posições ou movimentos no espaço. Ela permite a determinação da posição e orientação dos segmentos corporais, buscando medir os parâmetros cinemáticos do movimento, isto é, posição, orientação, velocidade e aceleração desses segmentos.

O instrumento básico para medidas cinemáticas é o baseado em câmeras de vídeo que registram a imagem do movimento ou as coordenadas de pontos de interesse e então através de software específico calculam as variáveis cinemáticas de interesse (Beer \& Johnston, 1991).

Há dois métodos distintos para a mensuração da curvatura da coluna utilizando cinemetria: usando câmeras infravermelhas e usando câmeras fotográficas. 


\subsubsection{CÂMERAS INFRAVERMELHAS}

As câmeras (Figura 11) operam por meio do registro da luz infravermelha refletida pelos marcadores. Os sistemas que registram luz infravermelha, baseados nos marcadores, utilizam hardwares específicos que realizam operações básicas de processamento de imagens. Isso Ihes confere uma vantagem, que é a de fornecer resultados rapidamente. Para isso, no entanto, são impostas restrições no número, proximidade e tamanho dos marcadores para a aquisição dos dados, no ambiente, no campo de visão das câmeras e nos movimentos a serem analisados.

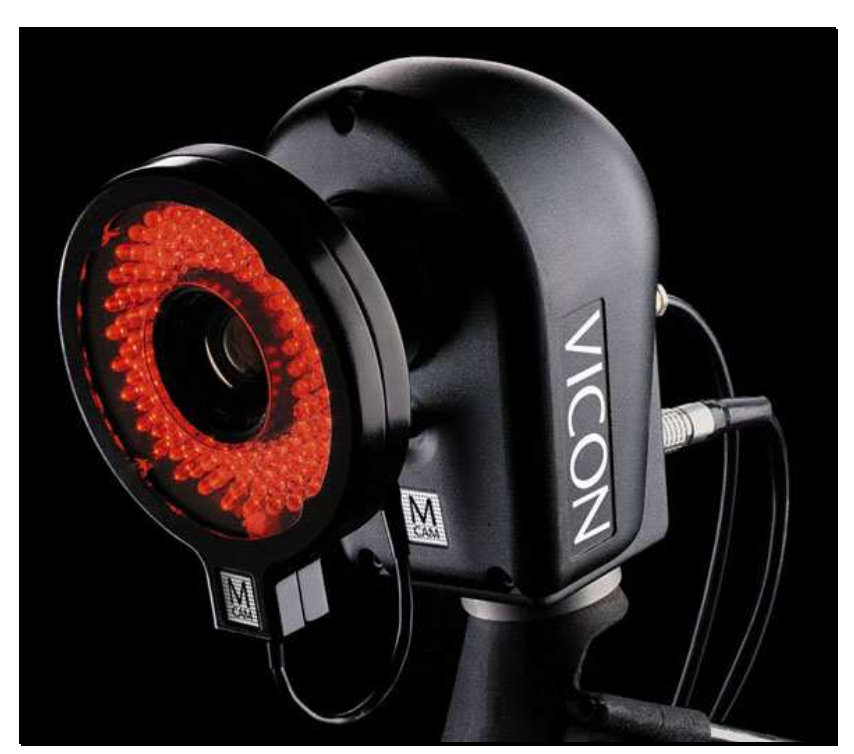

Figura 11 - Câmera infravermelha da VICON ${ }^{\circledR}$

Outra característica restritiva dos sistemas baseados em câmeras de infravermelho é que eles registram somente as coordenadas dos marcadores ${ }^{3}$ e não toda a imagem do movimento. Além disso, o sistema tem um custo que ultrapassa o milhar de dólares ${ }^{4}$.

Mas a grande vantagem desse método é a precisão dos dados coletados (alta freqüência), identificação e reprodução automática das coordenadas, assim como

\footnotetext{
${ }^{3}$ A câmera só registra luz infravermelha. Os marcadores servem como refletores das luzes infravermelhas emitidas pela própria câmera.

${ }^{4}$ Esses sistemas são utilizados no cinema para a criação de personagens digitalizados.
} 
sua reprodução em três dimensões no computador e a análise e tratamento dos dados em software específico do sistema.

Normand et. al. (2002) investigaram a correlação de coordenadas conhecidas no espaço e tamanhos de segmentos - de objetos inanimados, como paralelogramos - do raio-X com o BioTonix ${ }^{5}$. Foi encontrada uma correlação de 0,99 entre os tamanhos dos segmentos e também para os ângulos, concluindo que as coordenadas obtidas pela cinemetria são fidedignas.

Leroux et. al. (2000) utilizaram câmeras infravermelhas da Motion Analysis Corp. para avaliar a acurácia desse método não invasivo em mensurar as curvaturas da coluna vertebral em pacientes com escoliose, comparando com a radiografia. Foram utilizados 124 pacientes entre 6,2 e 18,7 anos e como parâmetros $T_{2}$ e $T_{12}$ para a cifose e $\mathrm{T}_{9}$ e $\mathrm{S}_{1}$ para a lordose. Por meio de apalpamento foram encontrados os processos espinhosos referente às vértebras pretendidas. Para a radiografia foi utilizado o método de Cobb para mensurar a curvatura, equivalentemente foi encontrada a curvatura no meio antropométrico por meio de análise geométrica. Verificaram uma grande correlação dos dados para ambos os métodos $(r=0.89$ para a cifose; $r=0.84$ para a lordose) além de mostrar ser uma amostragem muito homogênea $(I C C=0.94$ para cifose; $I C C=0.91$ para a lordose).

Já Descarreaux et. al. (2003) usaram uma metodologia experimentla semelhante para medir o posicionamento das vértebras da coluna cervical e os ângulos entre si através da cinemetria - com marcadores reflexivos - e compararam com dados obtidos por radiografia, encontrando uma correlação de 0,96 entre os métodos.

Chen et. al. (1997) realizaram um estudo semelhante, porém mediram o posicionamento das vértebras lombossacrais e os ângulos formados entre si. A correlação encontrada entre a radiografia e a cinemetria foi de 0,97.

\footnotetext{
${ }^{5}$ Software pago de avaliação postural que analisa três fotos - frontal, lateral e posterior - resultando nas medidas e ângulos dos segmentos.
} 
Esses estudos mostram a forte correlação entre a cinemetria e a radiografia, servindo assim como apoio para esse estudo, que se embasou na cinemetria para sua validação.

\subsubsection{CÂMERAS FOTOGRÁFICAS}

Apesar do método com câmeras infravermelhas demonstrar possuir uma acurácia e ser fortemente correlacionada com a o padrão ouro (radiografia), 0 sistema é muito caro e foge da realidade de consultórios de fisioterapia.

Em 1887, pesquisas sobre o andar do homem, levaram Étienne-Jules Marey a desenvolver a cronofotografia (Figura 12), que consistia em registrar em uma única placa a variação do movimento.

Já os alemães Braune \& Otto Fischer, em 1891, analisaram $\underline{\text { tridimensionalmente a marcha humana, desenvolvendo estudos sobre momentos de }}$ inércia de segmentos do corpo humano, assim como o centro de gravidade. Até hoje os dados coletados pelos alemães são utilizados em cálculos para a análise do movimento humano (NIGG, 1994).

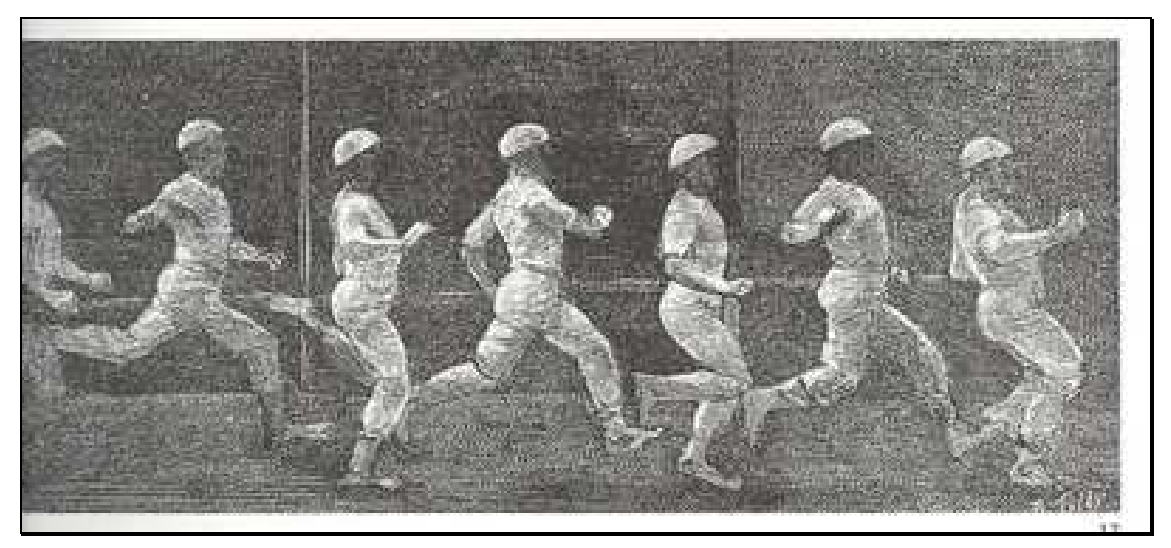

Figura 12 - Cronofotografia de Étienne-Jules Marey representando a corrida de um homem.

Fonte: do livro "La photographie du mouvement"

Muito se evoluiu nesses dois últimos séculos e atualmente existem inúmeros sistemas comerciais. A tecnologia permite, com o uso de aparelhos digitais, a conversão de dados analógicos para digitais e assim, cálculos de grandezas como 
posição no espaço, deslocamento, velocidade e aceleração, bem como ferramentas para processamento de dados, o processo para a análise por cinemetria é cada vez mais eficiente.

Uma foto representa o plano e a partir dela apenas não é possível fazer uma análise tridimensional. Métodos de reconstrução tridimensional têm sido estabelecidos, sendo um dos principais, desenvolvido para aplicações na engenharia, o chamado método DLT (Direct Linear Transformation). Essa metodologia é bem difundida na biomecânica atualmente (ABDEL-AZIZ \& KARARA; 1971).

A partir de duas fotos e um método de calibração, pode-se transpor a imagem bidimensional das fotos para uma reprodução tridimensional, sendo possível a mensuração de dados que necessitam do terceiro eixo para a análise.

Para que o DLT seja preciso, as duas fotos precisam que o objeto de análise permaneça imóvel. Uma solução para isso seria utilizar duas câmeras e fotografar a coluna vertebral ao mesmo tempo, porém, além de requerer duas câmeras, teria que ser feito um sistema de disparo para que ambas as fotos sejam tiradas simultaneamente.

Outra solução, adotada nesse estudo, seria utilizar um espelho simulando a segunda imagem que o DLT precisa. A imagem real e a virtual - reflexo do espelho - servem como duas fotos distintas, representando o mesmo estado da coluna vertebral.

\section{OBJETIVO}

O objetivo desse estudo foi desenvolver e validar uma ferramenta computacional para mensuração das curvaturas da coluna vertebral nos três eixos. Esta ferramenta computacional foi baseada num método simples e prático, e o programa desenvolvido é livre e com código aberto utilizando a linguagem gratuita de desenvolvimento Python. 


\section{MATERIAIS E MÉTODOS}

Os voluntários desse estudo não foram submetidos a nenhuma tarefa que comprometiam a sua saúde.

\subsection{AMOSTRA}

Foram utilizados dezoito indivíduos, sendo dez do sexo masculino e oito do sexo feminino. A idade variou entre 19 e 39 anos sendo a idade média $24 \pm 5$ anos. A estatura e massa dos indivíduos não são relevantes para o estudo. Todos os indivíduos só participaram do experimento após serem avisados oralmente, lerem e assinarem um termo de consentimento de acordo com o comitê de ética do Instituto de Psicologia da Universidade de São Paulo.

A heterogeneidade da amostra não influenciou no resultado uma vez que obtivemos dois resultados para cada indivíduo - por meio de métodos diferentes de mensuração - e esses resultados foram comparados entre si.

\subsection{MATERIAIS}

Para a realização do método que serviu de comparação, identificado por Cinemetria, foi utilizado o sistema $\operatorname{VICON}^{\circledR}$ composto de cinco câmeras infravermelhas de alta resolução (1280 x 1024 pixels) sendo mais do que suficiente para identificar os marcadores. A análise dos dados coletados foi feita no software do próprio sistema da $\operatorname{VICON}^{\circledR}$.

O segundo método, identificado como LoB Analytics ${ }^{6}$, contou com:

\footnotetext{
${ }^{6}$ O LOB Analytics precisa que o Python esteja instalado no computador. Não há especificações mínimas para que ele seja rodado, porém foram feitos testes em um PC586 com 32Mb de RAM que mostraram que o software foi perfeitamente executado. Ainda há necessidade de menos de $50 \mathrm{Mb}$ de espaço em disco para que o programa seja instalado junto com o Python.
} 
- Um espelho de fisioterapia, presente na grande maioria das clínicas;

- Uma câmera digital de três megapixels;

- Marcadores ${ }^{7}$ que indicaram pontos na pele correspondentes aos processos espinhosos do paciente;

- Um sistema de calibração que foi composto por quatro fios de prumo com oito marcações;

- O software desenvolvido em Python, ficando assim disponível para qualquer pessoa utilizá-lo e modificá-lo conforme sua necessidade.

O Python foi criado em 1991 por Guido van Rossum e está disponível gratuitamente para as mais diversas plataformas, desde Unix (Linux, FreeBSD, Solaris, MacOS $X$ etc.), Windows, .NET, versões antigas de MacOS até consoles de jogos eletrônicos ou mesmo alguns celulares e palmtops.

A escolha de Pyhton como linguagem de programação para 0 desenvolvimento do software não se deu apenas por ser uma linguagem de código aberto, mas também pela sua expressividade. A transformação das idéias em código é muito mais imediata e resulta em um código compacto mais legível. Pode-se pensar que o Python é uma linguagem sem muito poder por causa disso, porém é interpretada e orientada por objetos, com tipagem forte e dinâmica e gestão automática de memória, o que visa facilitar muito quem a programa. Atualmente a linguagem vem se expandindo no meio científico e o número de usuários vêm aumentando progressivamente como o seu suporte.

\footnotetext{
${ }^{7}$ Foram usados marcadores prateados por causa das câmeras infravermelhas. Para o LoB Analytics é necessário apenas a identificação do ponto, podendo ser usado qualquer tinta ou fita adesiva.
} 


\subsection{COLETA DE DADOS}

Com os dados coletados mediram-se as curvaturas da coluna vertebral, adquirindo o ângulo da cifose, lordose e, em sete casos, os ângulos das escolioses, todos através_do método de Cobb.

A coleta para ambos os métodos foram feitas ao mesmo tempo, evitando assim mudança da posição do indivíduo, consequentemente, posição dos marcadores.

Foram marcados os processos espinhosos da coluna vertebral do indivíduo com o auxílio de um fisioterapeuta - o mesmo durante todas as coletas -, feitas ao longo de dois dias. Foram identificados os processos espinhosos referentes à $\mathrm{C}_{7}, \mathrm{~T}_{1}$, $T_{2}, T_{4}, T_{6}, T_{8}, T_{10}, T_{12}, L_{4}$ e $S_{1}$. O indivíduo ficou em pé, relaxado, com as marcações devidamente colocadas, entre os quatro fios de prumo que serviram como calibrador. Ao lado do indivíduo foi posicionado o espelho; a máquina fotográfica foi posicionada de um jeito que conseguiu fotografar o indivíduo e seu reflexo no espelho, com todos os pontos de calibração. As câmeras da $\operatorname{VICON}^{\circledR}$ foram posicionadas em cima, uma em cada canto da sala e uma atrás do indivíduo (Figura 13).

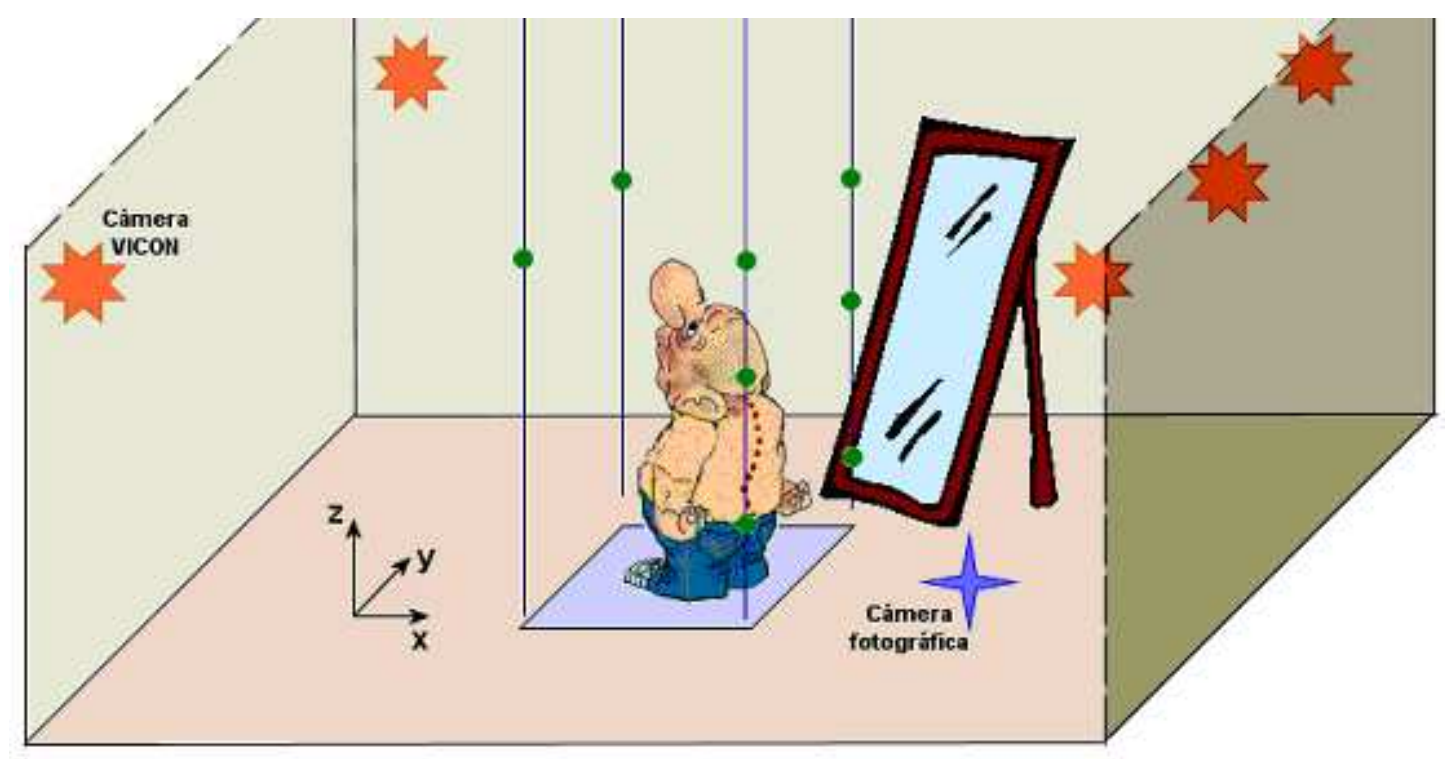

Figura 13 - Arranjo experimental para a coleta de dados 
Foram utilizados três sistemas de coordenadas para mensurar a cifose: $\mathrm{C}_{7} \mathrm{e}$ $\mathrm{T}_{12} ; \mathrm{T}_{1}$ e $\mathrm{T}_{12} ; \mathrm{T}_{2}$ e $\mathrm{T}_{12}$ (BRADFORD et. al., 1994; LEROUX et. al.; 2000).

Para a lordose foram utilizados dois sistemas de coordenadas: $T_{10}$ e $S_{1} ; T_{12}$ e $S_{1}$ (PROPST-PROCTOR \& BLECK, 1983; VOUTSINAS \& MACEWEN, 1986; BERNHARDT \& BRIDWELL, 1989; GELB et. al., 1995; VEDANTAM et. al., 1998).

Por fim, para a escoliose cada caso deve ser analisado diferentemente (LIMA, 2002). Foi identificada nos sete casos analisados uma deformidade entre as vértebras $C_{7}$ e $T_{6}$, duas entre $T_{2}$ e $T_{6}$ e mais quatro entre $C_{7}$ e $T_{4}$.

Essa não padronização de coordenadas servirá para verificar melhor a correlação entre os dois métodos utilizados (Cinemetria e Lob Analytics), e ver se ele é confiável, independente da metodologia adotada quando se aplica o método de Cobb.

\subsection{UTILIZANDO O LOB ANALYTICS}

Com a coleta feita pela $\operatorname{VICON}^{\circledR}$ já se têm as três coordenadas referentes à posição espacial de cada marcador. As coordenadas dos pontos de calibração foram medidas previamente.

O software desenvolvido em Python foi construído pensando na praticidade do profissional que irá executá-lo. Para informar os pontos que deseja analisar basta abrir a foto e clicar neles. Algo bem intuitivo e funcional.

Cada coleta, desde o momento da identificação dos processos espinhosos até a digitalização dos pontos e o resultado final do ângulo, durou cerca de vinte minutos. Lembrando que para o estudo foram identificados dez processos espinhosos, já em um consultório, o avaliador precisaria identificar apenas três para chegar ao ângulo. 
Foi ainda disponibilizado junto com o programa, um tutorial explicando detalhadamente como usá-lo.

Ao executar o programa é aberta a tela principal (Figura 14). Nela se escolhe o número de pontos_Pontos a digitalizar) que o usuário deseja transpor para três coordenadas assim como as oito coordenadas referentes à calibração (Calibração).

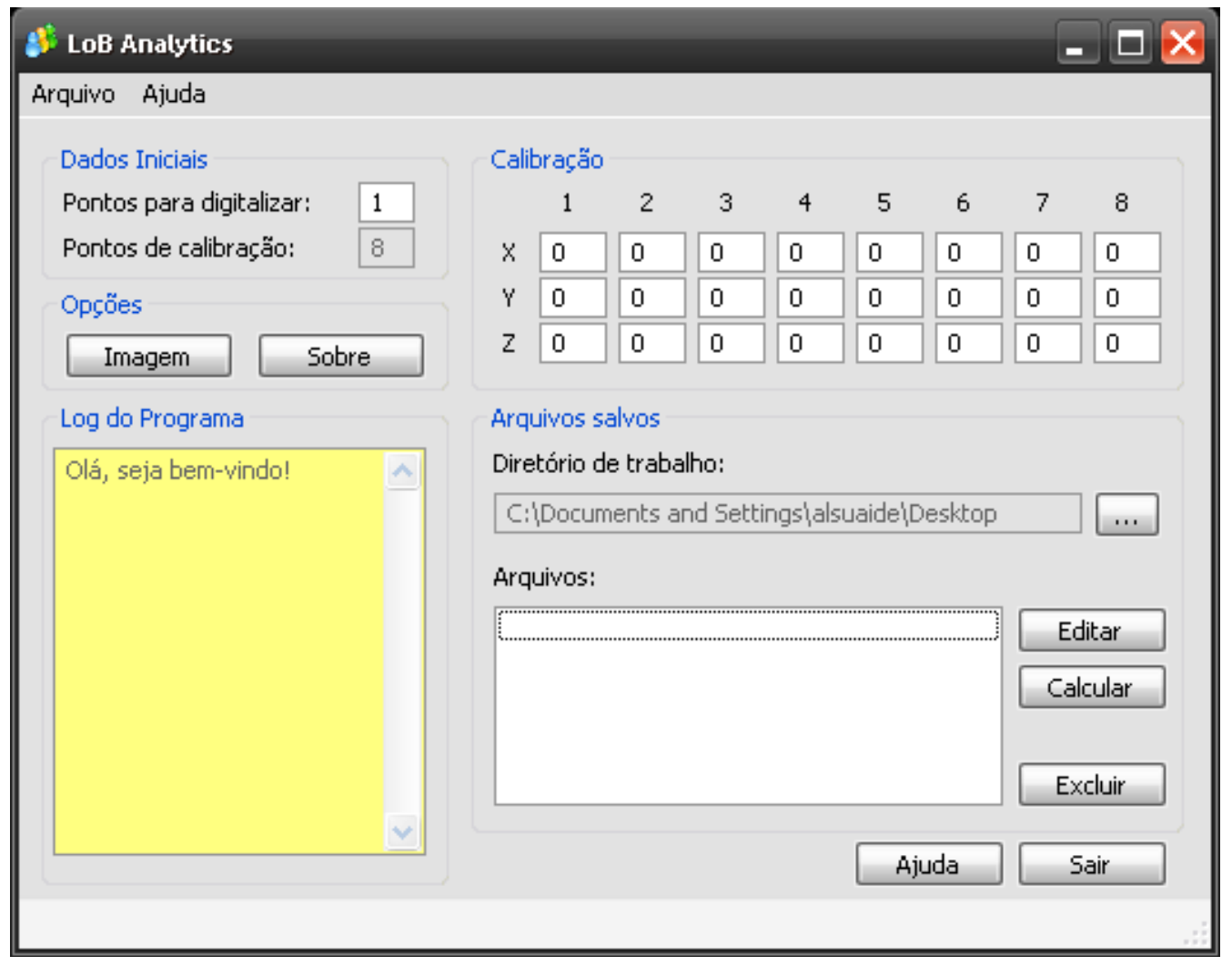

Figura 14 - Tela principal do software programado em Python

Os pontos de calibração são estáveis podendo ser medidos antes do início da coleta de dados. Eles são necessários para a extrapolação das coordenadas ' $X$ ' e ' $Y$ ' da foto - imagem bidimensional - em ' $X$ ', 'Y' e 'Z' pelo método $D L T$.

Ainda na tela principal, o usuário escolhe o seu diretório de trabalho, onde os cálculos serão gravados no computador, podendo administrá-los, visualizá-los ou excluí-los pelo próprio programa.

Inserido as primeiras informações, o usuário clica no botão "Imagem". Uma $\underline{\text { nova janela se abre (Figura 15) para a escolha da foto que será analisada. }}$ 


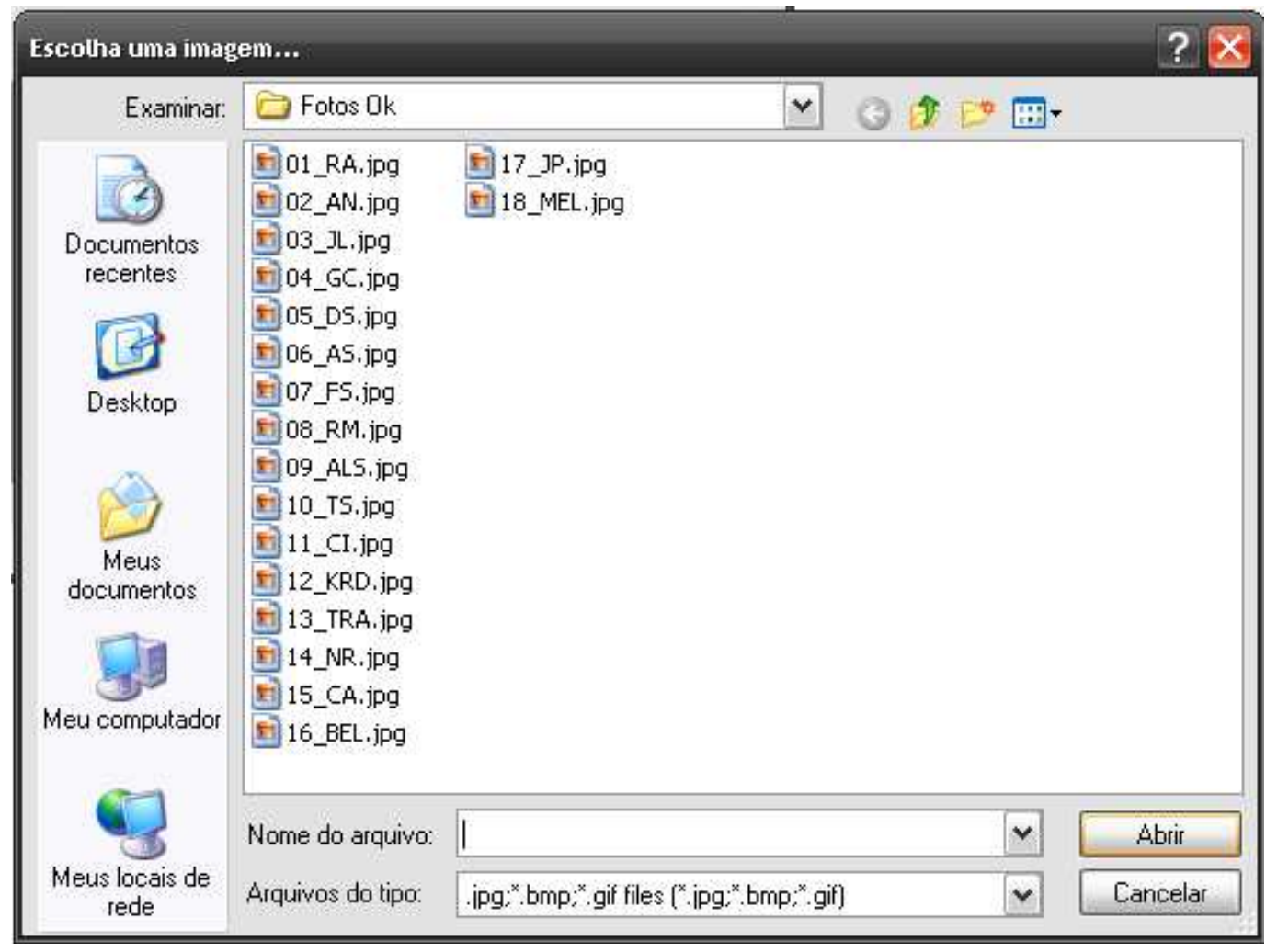

Figura 15 - Escolha de foto para a análise

Após escolher a foto ela é visualizada (Figura 16). Depois o usuário deve escolher os oito pontos de calibração clicando sobre eles na foto, com o botão esquerdo do mouse. Conforme o usuário clica nos pontos aparecem círculos azuis indicando quais pontos já foram interpretados pelo software.

É importante que seja seguida a mesma ordem informada para os oito pontos na tela principal do software. Caso o usuário clique em um ponto errado, basta clicar com o botão direito do mouse na foto, assim a última ação feita será desconsiderada, sendo possível a correção de possíveis "cliques" errados. 


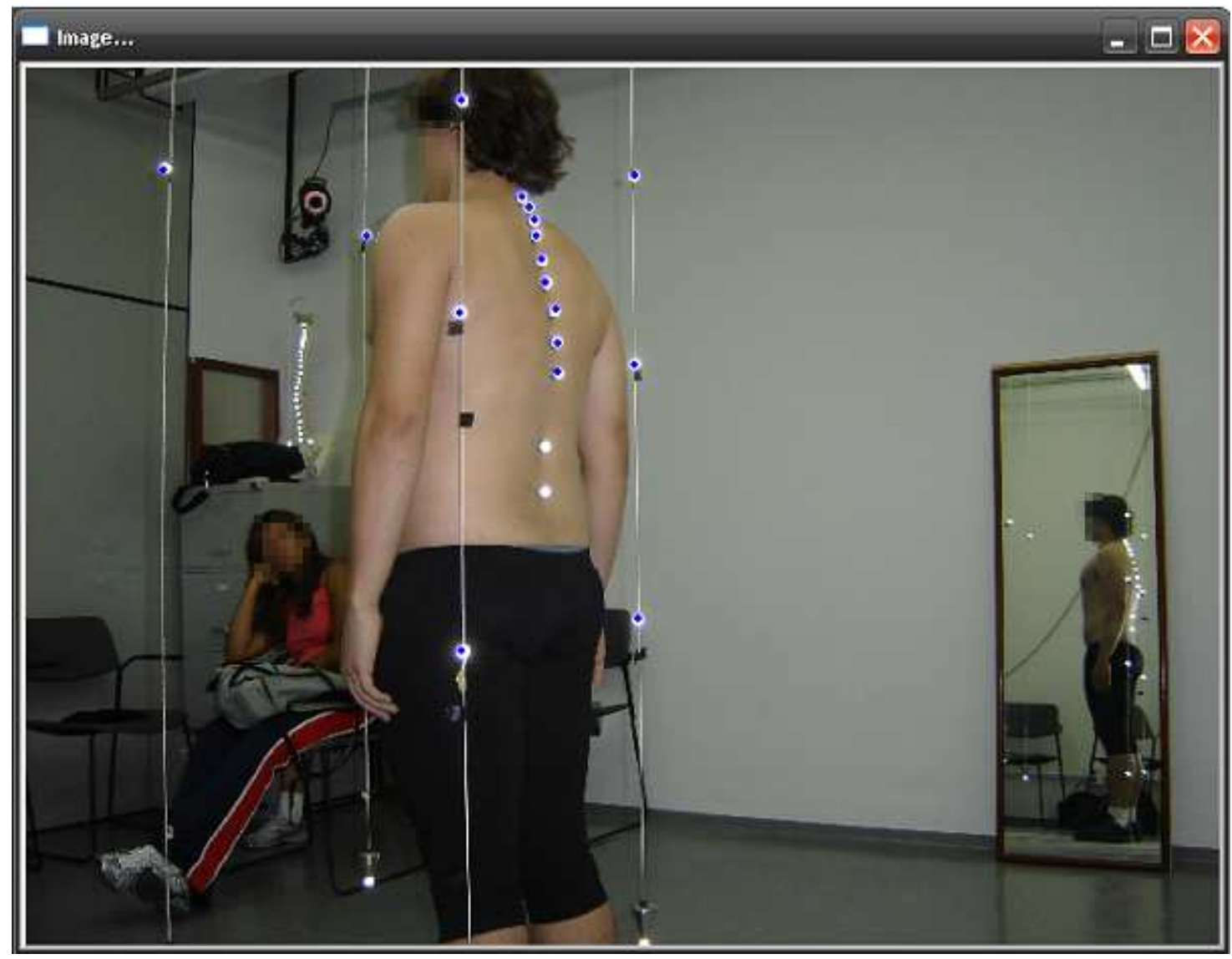

Figura 16 - Seleção dos pontos a serem analisados. Os pontos em azul são os que já foram clicados pelo usuário

O software ainda informa na área de log da tela principal (Log do Programa), as ações que já foram e que deverão ser feitas (Figura 17).

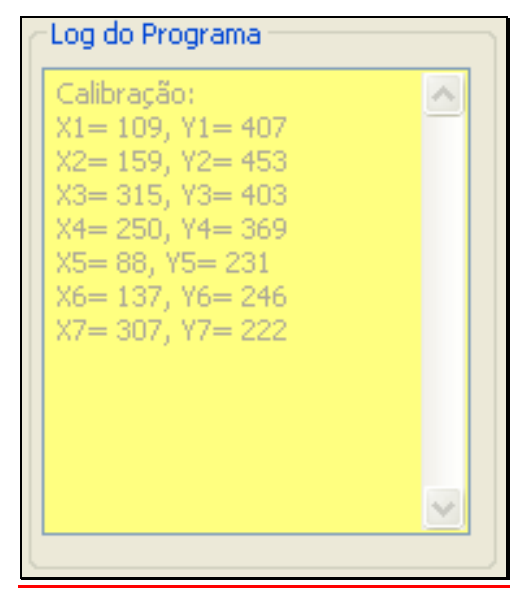

Figura 17 - Log do programa

A foto que será analisada deverá conter a imagem do paciente e os pontos de calibração (imagem real), assim como esses mesmo pontos refletidos no espelho (imagem virtual) (Figura 16). 
Com a foto aberta, o usuário deverá clicar nos oito pontos de calibração na imagem real. Após isso, deverá clicar nos pontos da coluna vertebral que deseja analisar, na imagem real também. Depois disso, os mesmo passos deverão ser seguidos para a imagem virtual (reflexo do espelho). É importante seguir a mesma seqüência adotada na imagem real. Caso o usuário clique no $T_{1}, T_{2}$ e $T_{12}$ nessa ordem, a mesma deverá ser clicada no reflexo do espelho.

Os dados calculados irão aparecer no log do programa (Figura 17), e 0 software perguntará se deseja salvar os mesmos dados em um arquivo texto para futura análise (Figura 18), os dados serão salvos no diretório escolhido na tela principal.

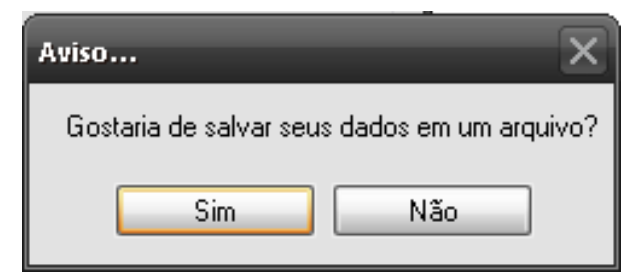

Figura 18 - Salvando os dados em disco

Caso o usuário opte por salvar o arquivo em disco, o cálculo do ângulo poderá ser feito selecionando o arquivo desejado e clicando no botão "Calcular".

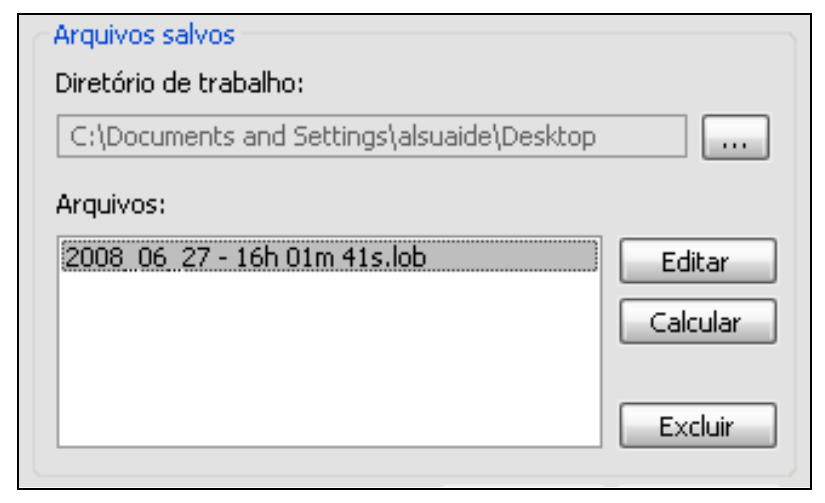

Figura 19 - Escolhendo o arquivo para calcular o ângulo

Na janela de cálculo (Figura 20), o usuário deve escolher os três pontos que formam o ângulo que deseja analisar. No caso desse estudo, um dos casos para medir o ângulo da cifose utiliza as vértebras $T_{1}$ e $T_{12}$. Para usar o método de Cobb é 
necessária uma terceira vértebra, no caso desse estudo, $\mathrm{T}_{4}$ - para ter um ângulo são necessários três pontos. O processo é explicado detalhadamente na Análise de Dados assim como o cálculo gerado pelo programa.

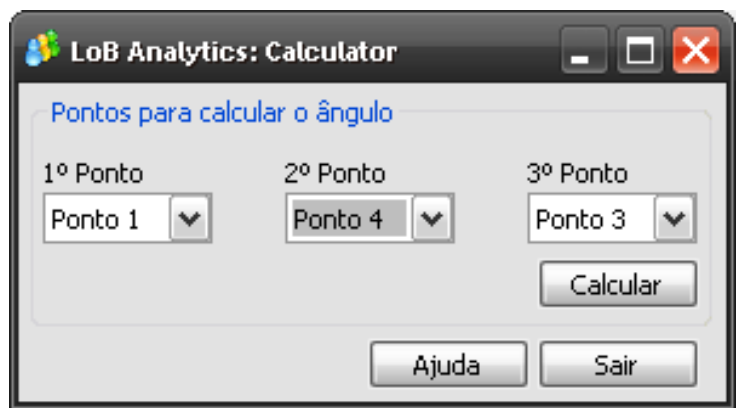

Figura 20 - Cálculo do ângulo

Os dois primeiros pontos representam as vértebras mais distantes da sua análise. $\mathrm{O}$ '3ํㅜ Ponto' será a vértebra do meio. Nesse caso, deve ser escolhido como ‘1 Ponto o equivalente a $T_{1}$; o ' 2 ํ Ponto' deverá ser o $T_{12}$; e finalmente o ' $3^{\circ}$ Ponto' deverá ser o equivalente ao $\mathrm{T}_{4}$. Escolhido os três pontos e clicando no botão 'Calcular', o valor do ângulo aparecerá ao lado do botão 'Calcular'.

\subsection{ANÁLISE DOS DADOS}

De posse das coordenadas dos processos espinhosos chegamos ao ângulo da cifose e lordose.

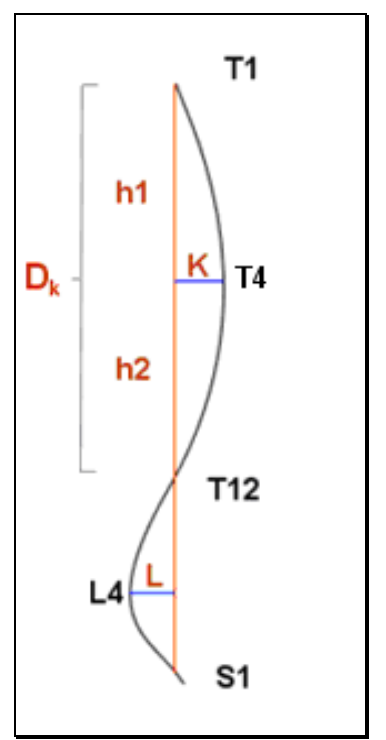

Figura 21 - Representação plana da cifose torácica e lordose lombar 
Primeiramente acha-se a distância $D_{k}$ de $T_{1}$ e $T_{2}$ e traça-se uma reta imaginária unindo os dois pontos (Figura 21). Uma reta também é traçada do ponto $T_{4}$ a linha $D_{k}$, obtendo assim um triângulo feito com os parâmetros da cifose (Figura 22).

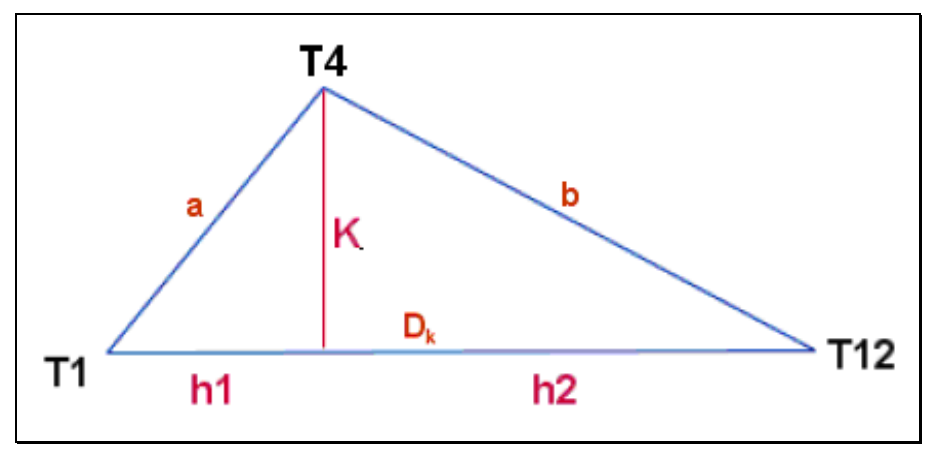

Figura 22 - Triângulo da cifose

É possível chegar nos valores de "a", "b" e $D_{k}$, pois sabendo as coordenadas ( $x$, y e z) de $T_{1}, T_{4}$ e $T_{12}$, é só usar a equação da distância de dois pontos (Equação $1)$.

$D=\sqrt{\left(x_{1}-x_{2}\right)^{2}+\left(y_{1}-y_{2}\right)^{2}+\left(z_{1}-z_{2}\right)^{2}}$

Equação 1

Onde $x_{1}, y_{1}, z_{1}$ e $x_{2}, y_{2}, z_{2}$ são as coordenadas dos dois pontos analisados para resultar a distância $D$.

Pela soma dos três lados do triângulo achamos o seu perímetro $(P)$, e pelo Teorema de Heron (Equação 2) encontramos a área do triângulo, com o auxílio dos segmentos $a$, $b$ e $D_{k}$ (Figura 22).

$A=\sqrt{P(P-a)(P-b)\left(P-D_{k}\right)}$

Equação 2

A área de um triângulo também se obtém calculando a metade do produto da medida da sua altura pela medida da sua base (Equação 3), como não se tem apenas o valor de K, encontramos seu valor. Sabendo a medida de K, por Pitágoras, acham-se os valores de $h_{1}$ e $h_{2}$. 
$A=\frac{D_{k} K}{2} \Leftrightarrow K=\frac{2 A}{D_{k}}$

Equação 3

É traçado um arco com a curvatura da cifose (Figura 23). Com as medidas de $h_{1}$ e $h_{2}$ pode-se achar o ângulo da cifose $\varphi$ pela soma de $\varphi_{1}$ e $\varphi_{2}$ (Equação 4) (LEROUX et. al.; 2000).

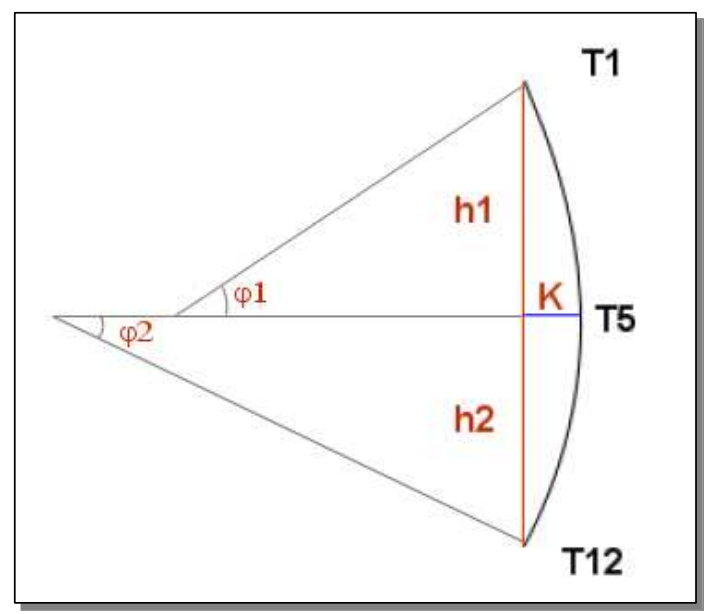

Figura 23 - Ângulo do arco da cifose

$$
\begin{aligned}
& \varphi_{1}=180-2 \operatorname{Arctan}\left(\frac{h_{1}}{K}\right) \\
& \varphi_{2}=180-2 \operatorname{Arctan}\left(\frac{h_{2}}{K}\right) \\
& \varphi=\varphi_{1}+\varphi_{2}
\end{aligned}
$$$$
\text { Equação } 4
$$

\section{RESULTADOS}

Os dados coletados por ambos os métodos - Cinemática e LoB Analytics resultaram na identificação das coordenadas no espaço - x, y e z -, de cada processo espinhoso marcado na foto. A Tabela 1 mostra um exemplo dos dados encontrados para um indivíduo. 
Tabela 1 - Coordenadas encontradas por Cinemetria e LOB Analytics para um indivíduo.

\begin{tabular}{cccc|ccc|ccc} 
& \multicolumn{3}{c}{ Cinemetria $(\mathbf{c m})$} & \multicolumn{3}{c}{ LoB Analytics $(\mathbf{c m})$} & \multicolumn{3}{c}{ Diferença Absoluta (cm) } \\
\cline { 2 - 11 } & $\mathbf{x}$ & $\mathbf{y}$ & $\mathbf{z}$ & $\mathbf{x}$ & $\mathbf{y}$ & $\mathbf{z}$ & $\mathbf{x}$ & $\mathbf{y}$ & $\mathbf{z}$ \\
\hline $\mathbf{C}_{\mathbf{7}}$ & 4,72 & 1,50 & 15,36 & 4,70 & 1,51 & 15,36 & 0,02 & 0,02 & 0,00 \\
$\mathbf{T}_{\mathbf{1}}$ & 4,83 & 1,47 & 15,12 & 4,81 & 1,49 & 15,11 & 0,02 & 0,02 & 0,01 \\
$\mathbf{T}_{\mathbf{2}}$ & 4,90 & 1,41 & 14,86 & 4,86 & 1,42 & 14,87 & 0,04 & 0,02 & 0,01 \\
$\mathbf{T}_{\mathbf{4}}$ & 5,02 & 1,42 & 14,45 & 5,00 & 1,40 & 14,43 & 0,02 & 0,02 & 0,02 \\
$\mathbf{T}_{\mathbf{6}}$ & 5,11 & 1,40 & 14,09 & 5,06 & 1,39 & 14,07 & 0,05 & 0,02 & 0,02 \\
$\mathbf{T}_{\mathbf{1 0}}$ & 5,27 & 1,42 & 13,16 & 5,24 & 1,45 & 13,16 & 0,02 & 0,03 & 0,00 \\
$\mathbf{T}_{\mathbf{1 2}}$ & 5,27 & 1,46 & 12,68 & 5,28 & 1,44 & 12,68 & 0,02 & 0,01 & 0,00 \\
$\mathbf{L}_{\mathbf{4}}$ & 4,98 & 1,50 & 11,58 & 4,96 & 1,51 & 11,58 & 0,03 & 0,01 & 0,00 \\
$\mathbf{S}_{\mathbf{2}}$ & 4,96 & 1,51 & 10,91 & 4,99 & 1,53 & 10,92 & 0,03 & 0,02 & 0,01 \\
\hline
\end{tabular}

Nesse caso, a média das diferenças absolutas é $0,02 \pm 0,01 \mathrm{~cm}$. Aumentando o espaço amostral para todos os dezoito indivíduos, a média da diferença absoluta é $0,03 \pm 0,03 \mathrm{~cm}$.

Para a mensuração da cifose torácica e lordose lombar foram usados os dados coletados de todos os dezoito indivíduos descritos na amostra. Já no caso da escoliose apenas sete casos foram medidos ${ }^{8}$.

Para a cifose torácica foram usados três sistemas de parâmetros para medir sua curvatura ${ }^{9}: \mathrm{C}_{7}$ e $\mathrm{T}_{12} ; \mathrm{T}_{1}$ e $\mathrm{T}_{12} ; \mathrm{T}_{2}$ e $\mathrm{T}_{12}$. Para a lordose lombar foram usados dois sistemas de parâmetros: $T_{10}$ e $S_{2} ; T_{12}$ e $S_{2}$. Já no caso da escoliose foram identificadas sete deformações próximas ao Grau 1, classificado por Ricard (1999). Como dito na revisão, a identificação da escoliose independe de vértebras fixas, sendo usadas como parâmetros as duas vértebras que mais se inclinam para o centro da curvatura (LIMA, 2002). Nesse estudo foram usados três sistemas de parâmetros: $\mathrm{C}_{7}$ e $\mathrm{T}_{6} ; \mathrm{T}_{2}$ e $\mathrm{T}_{6} ; \mathrm{C}_{7}$ e $\mathrm{T}_{4}$. Os dados para cada sistema de parâmetros foram organizados conforme a Tabela 2.

8 Visualmente foram identificados esses sete pelo avaliador. A partir disso foi feita a mensuração pelos métodos.

9 Essa diversificação apenas acrescenta ao trabalho, pois quanto mais pontos e resultados extraídos de ambos os métodos - Cinemetria e LOB Analytics -, mais preciso será o resultado da comparação entre eles. 
Tabela 2 - Ângulos da cifose torácica medidos através de $C_{7}$ e $T_{12}$.

\begin{tabular}{|c|c|c|c|c|c|c|c|c|c|}
\hline & \multicolumn{3}{|c|}{ Cinemetria (graus) } & \multicolumn{3}{|c|}{ LoB Analytics (graus) } & \multicolumn{3}{|c|}{ Diferença Absoluta (graus) } \\
\hline & $\varphi 1$ & $\varphi 2$ & $\varphi$ & $\varphi 1$ & $\varphi 2$ & $\varphi$ & $\varphi 1$ & $\varphi 2$ & $\varphi$ \\
\hline 1 & 15,8 & 8,5 & 24,3 & 15,2 & 8,4 & 23,6 & 0,6 & 0,1 & 0,7 \\
\hline 2 & 40,3 & 17,6 & 57,9 & 39,9 & 17,5 & 57,4 & 0,4 & 0,1 & 0,5 \\
\hline 3 & 32,6 & 12,3 & 44,9 & 32,9 & 13,3 & 46,2 & 0,4 & 1,0 & 1,3 \\
\hline 4 & 58,7 & 21,5 & 80,3 & 57,6 & 20,4 & 78,0 & 1,1 & 1,1 & 2,3 \\
\hline 5 & 44,2 & 18,0 & 62,2 & 42,6 & 17,1 & 59,8 & 1,5 & 0,9 & 2,4 \\
\hline 6 & 23,0 & 10,1 & 33,1 & 24,5 & 10,3 & 34,7 & 1,5 & 0,2 & 1,6 \\
\hline 7 & 39,9 & 13,3 & 53,2 & 41,9 & 15,6 & 57,6 & 2,1 & 2,3 & 4,4 \\
\hline 8 & 38,5 & 12,5 & 51,0 & 38,7 & 14,5 & 53,1 & 0,2 & 2,0 & 2,1 \\
\hline 9 & 38,7 & 21,4 & 60,2 & 38,5 & 18,7 & 57,2 & 0,2 & 2,8 & 3,0 \\
\hline 10 & 36,8 & 14,8 & 51,6 & 38,6 & 16,8 & 55,4 & 1,9 & 1,9 & 3,8 \\
\hline 11 & 30,6 & 14,8 & 45,4 & 30,6 & 10,3 & 40,9 & 0,0 & 4,5 & 4,5 \\
\hline 12 & 31,0 & 11,6 & 42,6 & 34,5 & 13,8 & 48,3 & 3,5 & 2,1 & 5,7 \\
\hline 13 & 29,7 & 15,8 & 45,5 & 31,3 & 14,6 & 45,9 & 1,6 & 1,2 & 0,4 \\
\hline 14 & 28,7 & 15,2 & 43,9 & 31,3 & 17,8 & 49,1 & 2,6 & 2,5 & 5,1 \\
\hline 15 & 16,9 & 7,0 & 23,9 & 14,5 & 6,9 & 21,4 & 2,4 & 0,1 & 2,5 \\
\hline 16 & 20,9 & 10,8 & 31,6 & 22,1 & 11,5 & 33,6 & 1,2 & 0,8 & 2,0 \\
\hline 17 & 22,8 & 9,6 & 32,5 & 23,7 & 10,6 & 34,3 & 0,9 & 1,0 & 1,9 \\
\hline 18 & 40,0 & 22,6 & 62,6 & 41,2 & 22,5 & 63,7 & 1,2 & 0,1 & 1,1 \\
\hline Média & 32,7 & 14,3 & 47,0 & 33,3 & 14,5 & 47,8 & 1,3 & 1,4 & 2,5 \\
\hline Desvio & 10,7 & 4,6 & 14,7 & 10,7 & 4,2 & 14,5 & 0,9 & 1,2 & 1,6 \\
\hline
\end{tabular}

Já a Tabela 3 consolida as informações encontradas para os ângulos da cifose torácica e lordose lombar, usando todos os sistemas de parâmetros citados anteriormente.

A média e desvio padrão encontrados para o ângulo da cifose torácica, usando $C_{7}$ e $T_{12}$ como parâmetros, foi $47,0 \pm 14,7^{\circ}$ com a Cinemetria e $47,8 \pm 14,5^{\circ}$ com o LoB Analytics A média da diferença absoluta foi $2,5 \pm 1,6^{\circ}$ e a correlação encontrada entre os dois métodos foi de 0,98.

Utilizando $T_{1}$ e $T_{2}$ foi obtido para o ângulo da cifose torácica uma média de $42,8 \pm 13,6^{\circ}$ utilizando a Cinemetria e $42,8 \pm 13,5^{\circ}$ utilizando o LoB Analytics. A diferença absoluta entre os dois métodos foi de $3,1 \pm 1,3^{\circ}$ e a correlação entre eles foi de 0,97 (Tabela 3).

Já com as vértebras $T_{2}$ e $T_{12}$ chegou-se a $37,9 \pm 13,6^{\circ}$ e $38,5 \pm 12,8^{\circ}$ com o auxílio da Cinemetria e Lob Analytics respectivamente. A diferença absoluta entre os métodos foi de $3,1 \pm 1,7^{\circ}$ e a correlação foi 0,97 também (Tabela 3 ). 
Tabela 3 - Média, desvio padrão e intervalo dos ângulos medidos.

\begin{tabular}{|c|c|c|c|c|c|c|}
\hline & & & $\begin{array}{c}\text { Cinemetria } \\
\text { (graus) }\end{array}$ & $\begin{array}{l}\text { LoB Analytics } \\
\text { (graus) }\end{array}$ & $\begin{array}{c}\text { Diferença } \\
\text { Absoluta } \\
\text { (graus) } \\
\end{array}$ & $\begin{array}{c}\text { Correlação de } \\
\text { Pearson } \\
(r)\end{array}$ \\
\hline \multirow{9}{*}{$\begin{array}{l}\text { 山ू } \\
\text { Oे } \\
\frac{1}{0}\end{array}$} & & Média & 47,0 & 47,8 & 2,5 & \\
\hline & $C_{7} \sim T_{12}$ & DP & 14,7 & 14,5 & 1,6 & 0,98 \\
\hline & & Intervalo & 23,9 a 80,3 & 21,4 a 78,0 & 0,4 a 5,7 & \\
\hline & & Média & 42,8 & 42,8 & 3,1 & \\
\hline & $T_{1} \sim T_{12}$ & DP & 13,6 & 13,5 & 1,3 & 0,97 \\
\hline & & Intervalo & 19,3 a 75,2 & 20,8 a 70,4 & 0,2 a 4,8 & \\
\hline & & Média & 37,9 & 38,5 & 3,1 & \\
\hline & $T_{2} \sim T_{12}$ & DP & 13,6 & 12,8 & 1,7 & 0,97 \\
\hline & & Intervalo & 17,6 a 69,9 & 20,0 a 68,0 & 0,1 a 6,2 & \\
\hline \multirow{6}{*}{ 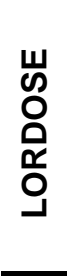 } & & Média & 48,8 & 49,4 & 3,5 & \\
\hline & $\mathrm{T}_{10} \sim \mathrm{S}_{2}$ & DP & 22,6 & 20,8 & 2,0 & 0,99 \\
\hline & & Intervalo & 8,7 a 88,1 & 10,3 a 87,4 & 0,7 a 9,4 & \\
\hline & & Média & 48,6 & 49,5 & 4,0 & \\
\hline & $\mathrm{T}_{12} \sim \mathrm{S}_{2}$ & DP & 22,9 & 21,3 & 3,3 & 0,97 \\
\hline & & Intervalo & 8,1 a 91,9 & 10,6 a 90,8 & 1,1 a 13,7 & \\
\hline
\end{tabular}

Para a lordose lombar utilizaram-se dois sistemas de parâmetros. Usando $T_{10}$ e $S_{2}$ foi encontrado $48,8 \pm 22,6^{\circ}$ com a Cinemetria e 49,4 $\pm 20,8^{\circ}$ com o LoB Analytics. A diferença absoluta entre os métodos foi $3,5 \pm 2,0^{\circ}$ e a correlação entre eles foi de 0,99 (Tabela 3).

Já com $T_{12}$ e $S_{2}$ foi encontrado $48,6 \pm 22,9^{\circ}$ e 49,5 $\pm 21,3^{\circ}$ com o auxílio da Cinemetria e $L O B$ Analytics respectivamente. A correlação entre os métodos foi de 0,97 e a diferença absoluta foi $4,0 \pm 3,3^{\circ}$ (Tabela 3 ).

$\mathrm{Na}$ Tabela 4 são conhecidas as medidas feitas para os sete casos de escoliose analisados. Foi encontrada uma média de $21,7 \pm 4,2^{\circ}$ com o auxílio da Cinemetria e $21,3 \pm 4,8^{\circ}$ com o uso do LoB Analytics. A partir dos ângulos se vê uma média das diferenças absolutas de $1,4 \pm 0,8^{\circ}$. Ainda com esses dados, foi encontrada uma correlação de 0,94. A maior diferença absoluta entre os métodos encontrada no caso da escoliose foi de 3,0 . 
Tabela 4 - Ângulos da escoliose medidos pela cinemetria e LoB Analytics.

\begin{tabular}{|c|c|c|c|c|c|c|c|c|c|}
\hline & \multicolumn{3}{|c|}{ Cinemetria (graus) } & \multicolumn{3}{|c|}{ LoB Analytics (graus) } & \multicolumn{3}{|c|}{ Diferença Absoluta (graus) } \\
\hline & $\varphi 1$ & $\varphi 2$ & $\varphi$ & $\varphi 1$ & $\varphi 2$ & $\varphi$ & $\varphi 1$ & $\varphi 2$ & $\varphi$ \\
\hline $\mathrm{C}_{7} \sim \mathrm{T}_{2} \sim \mathrm{T}_{6}$ & 12,8 & 8,6 & 21,4 & 10,7 & 7,8 & 18,4 & 2,2 & 0,8 & 3,0 \\
\hline$T_{2} \sim T_{4} \sim T_{6}$ & 8,2 & 10,0 & 18,2 & 8,4 & 9,0 & 17,4 & 0,2 & 1,0 & 0,7 \\
\hline$T_{2} \sim T_{4} \sim T_{6}$ & 8,5 & 8,0 & 16,5 & 8,0 & 9,7 & 17,7 & 0,5 & 1,7 & 1,2 \\
\hline $\mathrm{C}_{7} \sim \mathrm{T}_{2} \sim \mathrm{T}_{4}$ & 12,5 & 16,0 & 28,4 & 14,0 & 15,5 & 29,6 & 1,5 & 0,4 & 1,1 \\
\hline $\mathrm{C}_{7} \sim \mathrm{T}_{2} \sim \mathrm{T}_{4}$ & 11,1 & 15,0 & 26,1 & 10,8 & 14,5 & 25,3 & 0,3 & 0,5 & 0,8 \\
\hline $\mathrm{C}_{7} \sim \mathrm{T}_{2} \sim \mathrm{T}_{4}$ & 10,8 & 11,3 & 22,1 & 10,0 & 13,2 & 23,2 & 0,8 & 1,9 & 1,1 \\
\hline$C_{7} \sim T_{2} \sim T_{4}$ & 9,3 & 9,9 & 19,2 & 7,7 & 9,9 & 17,6 & 1,5 & 0,1 & 1,6 \\
\hline Média & 10,4 & 11,3 & 21,7 & 9,9 & 11,4 & 21,3 & 1,0 & 0,9 & 1,4 \\
\hline Desvio & 1,9 & 3,1 & 4,3 & 2,2 & 3,0 & 4,8 & 0,7 & 0,7 & 0,8 \\
\hline
\end{tabular}

Com os resultados, pode-se ver a diferença absoluta entre os ângulos medidos pelos dois métodos. Na Tabela 3 e Tabela 4 têm-se a coluna Diferença Absoluta que indica a média, desvio padrão e o intervalo destas levando em consideração a Cinemetria e o LOB Analytics. Essas informações foram agrupadas na Tabela 5.

Tabela 5 - Quantidade de indivíduos agrupados pela diferença absoluta entre os métodos

\begin{tabular}{|c|c|c|c|c|c|}
\hline & & $\leq 3$ & $3^{\circ}<x \leq 5$ & $5^{\circ}<x \leq 80$ & $80<x \leq 14$ \\
\hline \multirow{3}{*}{$\begin{array}{l}山 \\
\text { О } \\
\frac{1}{0}\end{array}$} & $C_{7} \sim T_{12}$ & $13(72,2 \%)$ & $3(16,7 \%)$ & $2(11,1 \%)$ & 0 \\
\hline & $T_{1} \sim T_{12}$ & $8(44,4 \%)$ & $10(55,6 \%)$ & 0 & 0 \\
\hline & $T_{2} \sim T_{12}$ & $10(55,6 \%)$ & $6(33,3 \%)$ & $2(11,1 \%)$ & 0 \\
\hline \multirow{2}{*}{ 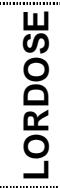 } & $\mathrm{T}_{10} \sim \mathrm{S}_{2}$ & $8(44,4 \%)$ & $8(44,4 \%)$ & $1(5,6 \%)$ & $1(5,6 \%)$ \\
\hline & $T_{12} \sim S_{2}$ & $8(44,4 \%)$ & $7(38,9 \%)$ & $1(5,6 \%)$ & $2(11,1 \%)$ \\
\hline \multicolumn{2}{|c|}{ ESCOLIOSE } & $7(100 \%)$ & 0 & 0 & 0 \\
\hline & Total & $54(55,7 \%)$ & $34(35,0 \%)$ & $6(6,2 \%)$ & $3(3,1 \%)$ \\
\hline
\end{tabular}

Para a medição do ângulo da cifose utilizando $C_{7}$ e $T_{12}$, treze casos mostraram uma diferença absoluta menor ou igual que $3^{\circ}$ - dos dezoito possíveis. Esse número cai para dez quando usado $T_{2}$ e $T_{12}$ como parâmetros, oito nos demais casos de cifose e lordose e sete para escoliose, totalizando 54 incidências em 97 $55,7 \%$. Já no lado oposto, foram encontrados três casos - 3,1\% - onde a diferença absoluta dos ângulos medidos pelos dois métodos foi maior que $8^{\circ}$ e menor ou igual 
a $14^{\circ}$ - sendo os três casos para lordose. Na escoliose todas as diferenças absolutas entre os dois métodos foram menor que 3‥

A fim de verificar se há uma tendência nos dados gerados pelo $L o B$ Analytics em relação aos dados gerados pela Cinemetria foi criada a Tabela 6 que mostra a relação entre os ângulos medidos por ambos os métodos. Foi agrupado o número de vezes que os ângulos gerados pelo $L O B$ Analytics foram maior e menor que os gerados pela Cinemetria.

Tabela 6 - Total de ângulos metidos pelo LoB Analytics em relação aos da Cinemetria

\begin{tabular}{ccccc} 
& \multicolumn{2}{c}{ LoB Analytics $>$ Cinemetria } & \multicolumn{2}{c}{ LoB Analytics < Cinemetria } \\
\cline { 2 - 5 } & Absoluto & Percentual & Absoluto & Percentual \\
\hline Cifose $\left(\mathbf{C}_{7} \sim \mathbf{T}_{12}\right)$ & 11 & $61.1 \%$ & 7 & $38.9 \%$ \\
Cifose $\left(\mathrm{T}_{1} \sim \mathrm{T}_{12}\right)$ & 10 & $55.6 \%$ & 8 & $44.4 \%$ \\
Cifose $\left(\mathrm{T}_{2} \sim \mathrm{T}_{12}\right)$ & 10 & $55.6 \%$ & 8 & $44.4 \%$ \\
Lordose $\left(\mathrm{T}_{10} \sim \mathrm{S}_{2}\right)$ & 8 & $44.4 \%$ & 10 & $55.6 \%$ \\
Lordose $\left(\mathrm{T}_{12} \sim \mathrm{S}_{2}\right)$ & 10 & $55.6 \%$ & 8 & $44.4 \%$ \\
Escoliose & 3 & $42.9 \%$ & 4 & $57.1 \%$ \\
\hline Média & $57.4 \%$ & & $42.6 \%$ \\
\hline
\end{tabular}

A média de ocorrência em que os ângulos calculados pelo $L O B$ Analytics foram maior que os calculados pela Cinemetria foi de 57,4\%. Como os dados seguem uma distribuição binomial, foi feito um teste de probabilidade para ver se eles são tendenciosos, já que houve uma maior ocorrência dos ângulos calculados pelo LoB Analytics serem maiores.

A Figura 24 mostra a distribuição dos ângulos para a cifose torácica encontrados pelo $L o B$ Analytics em relação a Cinemetria, quando usado $C_{7}$ e $T_{12}$.

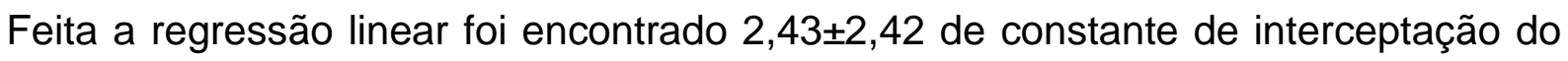
eixo vertical - ângulos obtidos pela Cinemetria - e 0,96 $\pm 0,05$ de coeficiente linear. 


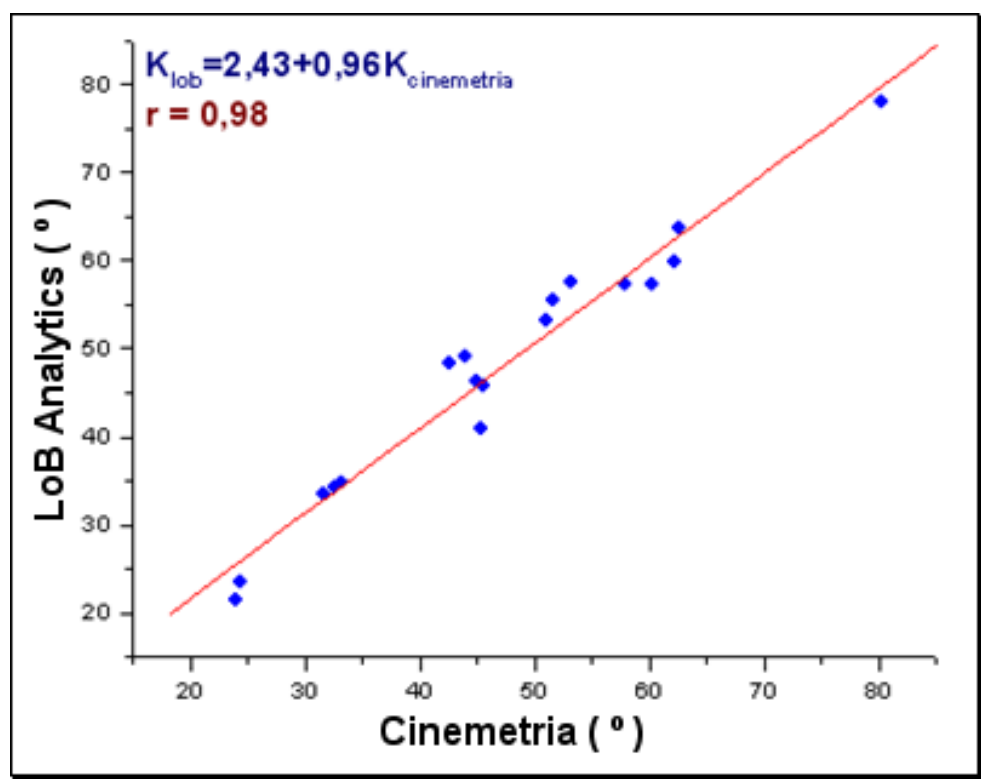

Figura 24 - Ângulos da cifose torácica obtidos através de $C_{7}$ e $T_{12}$.

O mesmo foi feito para os demais ângulos encontrados para a cifose e lordose. A Figura 25 mostra a mesma distribuição, porém com os ângulos encontrados a partir das vértebras $T_{1}$ e $T_{12}$. As constantes de interceptação e

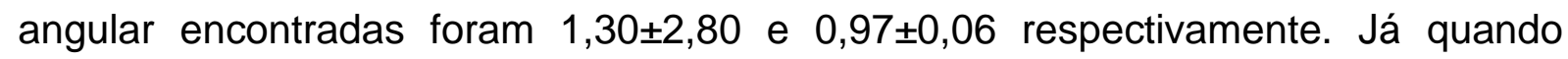

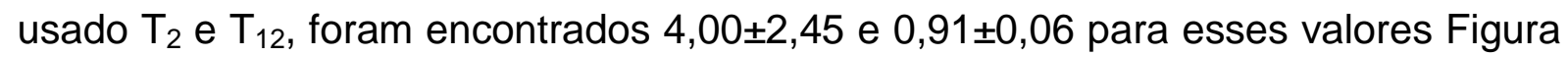
26.

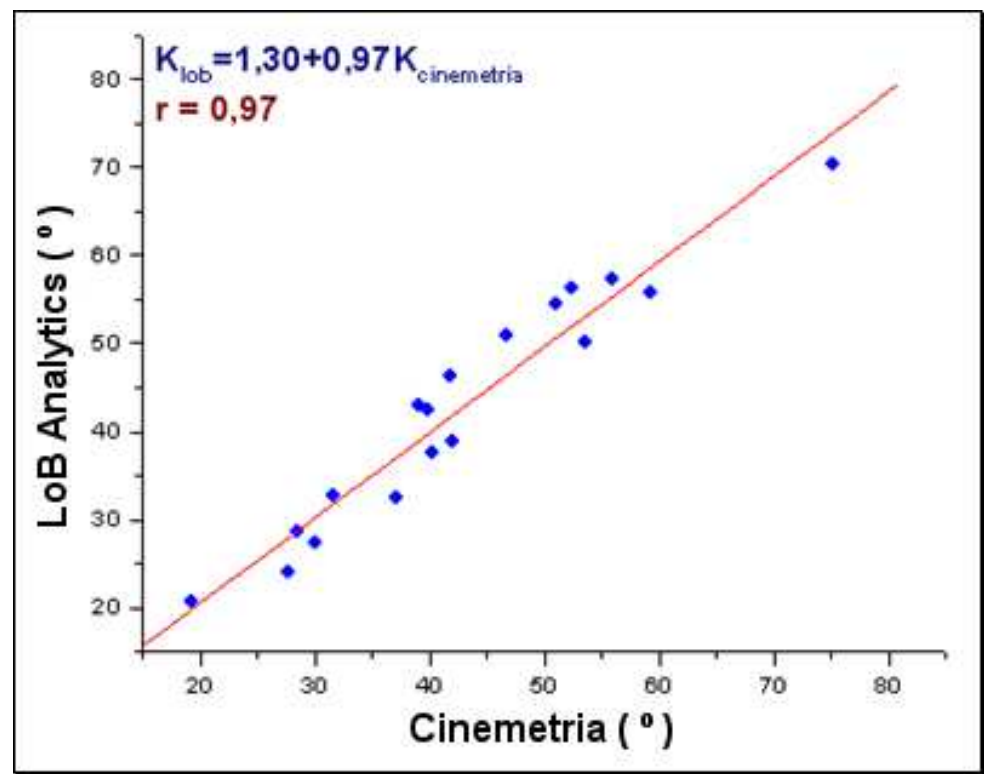

Figura 25 - Ângulos da cifose torácica obtidos através de $T_{1}$ e $T_{12}$. 


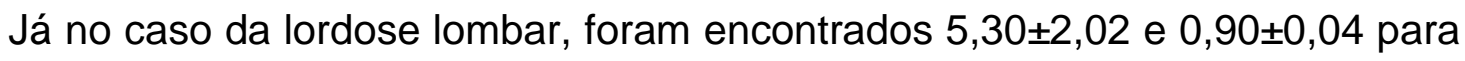
as constantes de interceptação e angular quando usado T10 e S2 para mensurar o

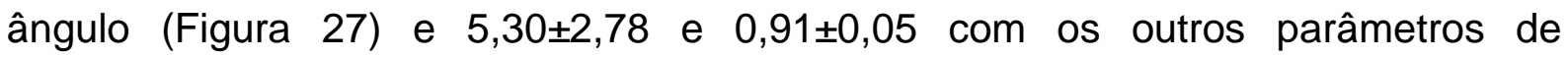
mensuração: T12 e S2 (Figura 28).

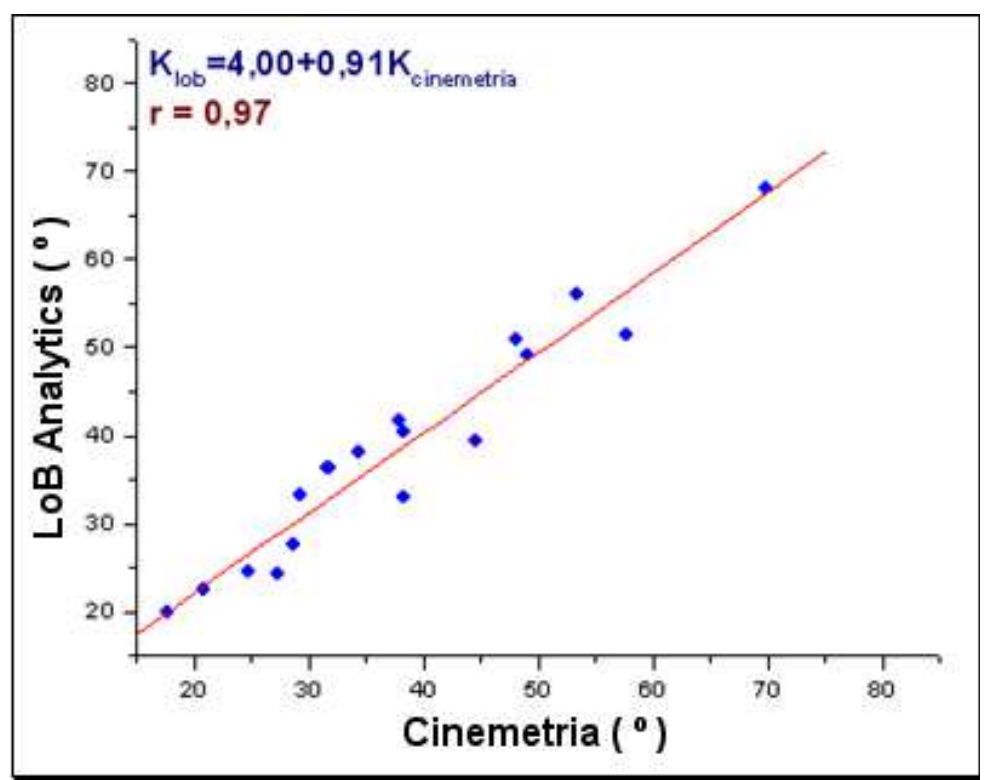

Figura 26 - Ângulos da cifose torácica obtidos através de $T_{2}$ e $T_{12}$.

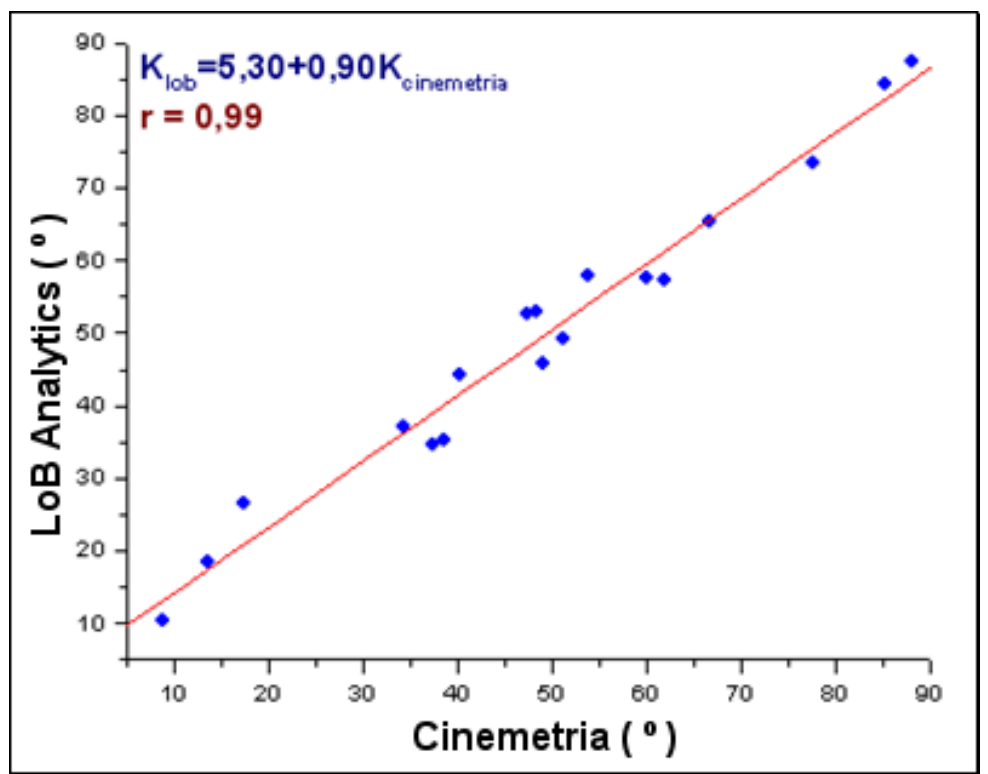

Figura 27 - Ângulos da lordose lombar obtidos através de $T_{10}$ e $S_{2}$. 


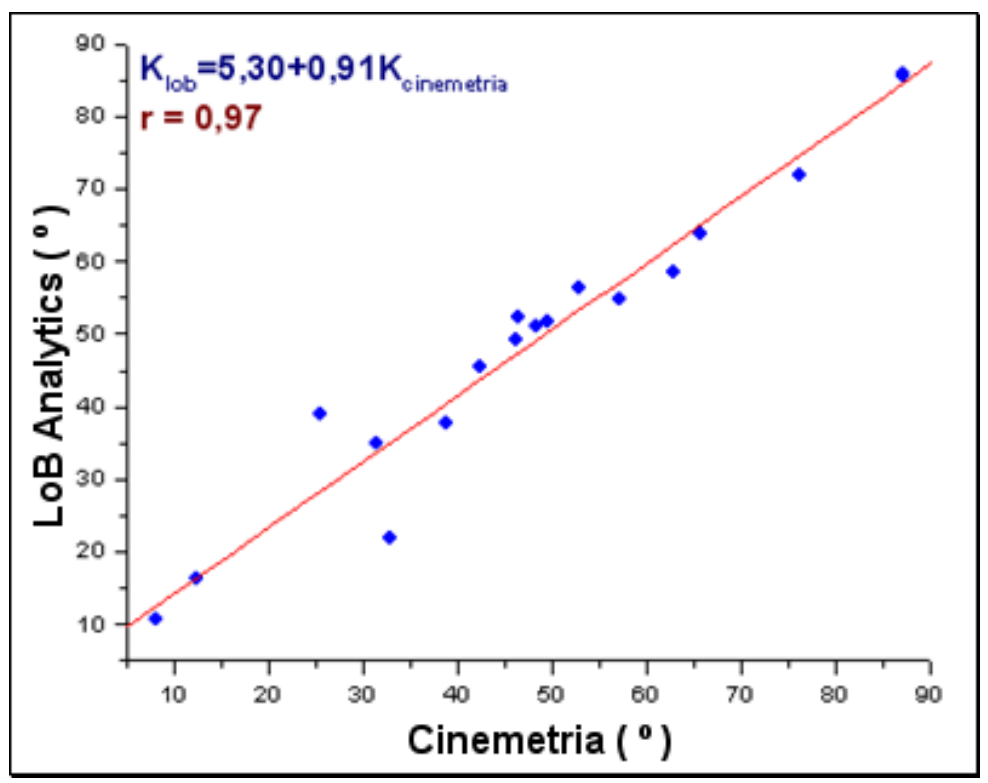

Figura 28 - Ângulos da lordose lombar obtidos através de $\mathrm{T}_{12}$ e $\mathrm{S}_{2}$.

A mesma regressão linear foi feita para os ângulos da escoliose encontrados por ambos os métodos. A constante de interceptação encontrada foi $-1,49 \pm 3,70$ e a constante linear encontrada foi 1,05 $\pm 0,17$ (Figura 29).

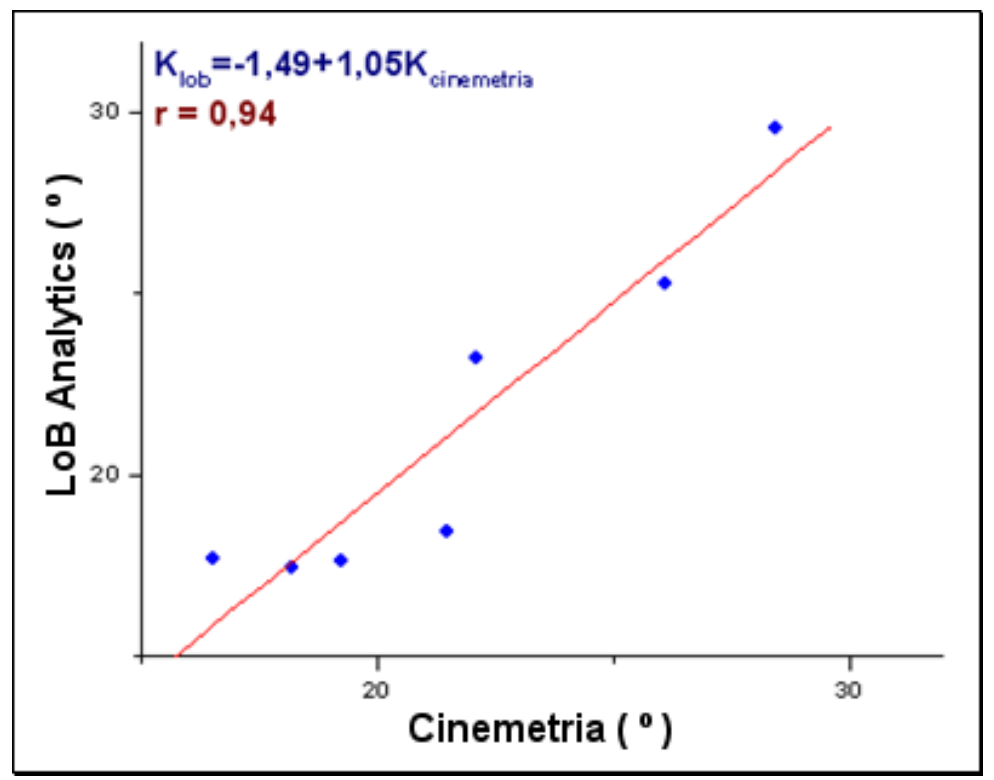

Figura 29 - Ângulos da escoliose.

Juntando todos os 97 ângulos coletados foi encontrada uma correlação de 0,98 entre os métodos. Para a Cinemetria teve-se uma média de $43,4 \pm 18,5$ e para o

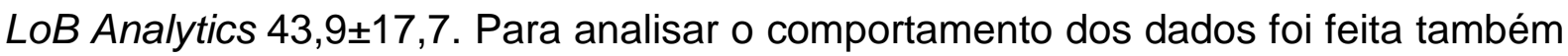




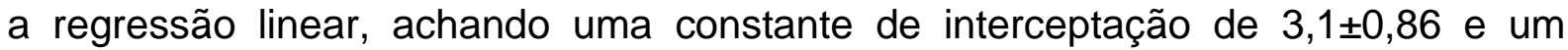
coeficiente angular de 0,94 $\pm 0,02$ (Figura 30).

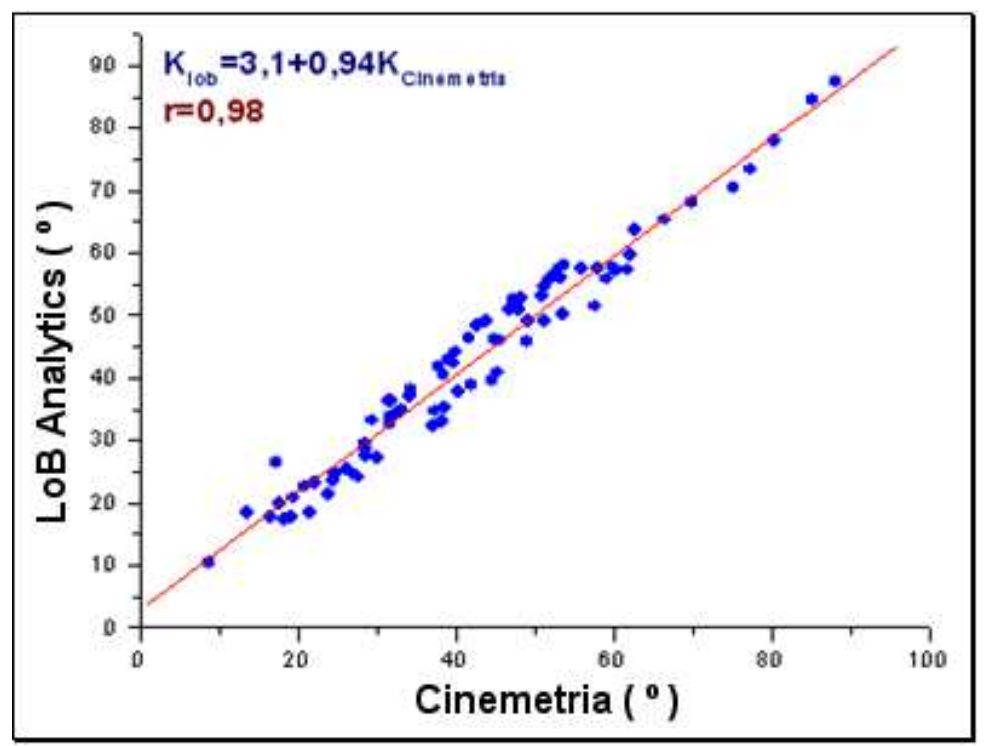

Figura 30 - Todos os ângulos consolidados ( $n=97)$

\section{DISCUSSÃO}

Esse estudo teve como objetivo desenvolver um software livre - LoB Analytics - no qual seria possível, de modo simples e com poucos recursos, medir as curvaturas da coluna vertebral, obtendo o ângulo da cifose, lordose e escoliose.

Alguns métodos para mensurar esses ângulos foram expostos e, apesar de terem seus méritos, todos apresentavam carências. Uma motivação para 0 acontecimento desse trabalho foi supri-las e, ao mesmo tempo, demonstrar uma facilidade de aplicação e confiabilidade necessárias para que seu uso se torne uma realidade.

A facilidade da medição do ângulo da cifose torácica, lordose lombar ou escoliose se mostra no tempo para a obtenção do mesmo. Nesse estudo foram marcados pontos além dos necessários em uma utilização clínica. Para o propósito de mensurar um ângulo da cifose torácica, por exemplo, basta marcar três pontos no 
individuo. Feito isso, posicionar o indivíduo entre a calibração, posicionar o espelho e tirar a foto não gastarão mais que dez minutos. Para o uso do LoB Analytics, cerca de cinco minutos são o suficiente - nesse estudo, da coleta até o cálculo do ângulo pelo LoB Analytics foram gastos cerca de vinte minutos em média.

Infelizmente a comparação direta com a radiografia não foi possível nesse estudo, porém estudos foram apresentados na revisão de literatura (2.4.8.1) retratando a forte correlação entre os dados obtidos através da radiografia com os dados obtidos utilizando um sistema de câmeras infravermelhas. O foco dos estudos apresentados eram ângulos extraídos da curvatura da coluna vertebral, assim como nesse.

Essa forte correlação serviu como ponte para adotar a Cinemetria como validador do LoB Analytics, comparando os dados obtidos por ambos os métodos ${ }^{10}$.

Apesar de utilizados dezoito sujeitos, foram obtidos ao todo 97 ângulos ${ }^{11}$, sendo realizados três modos de calcular a cifose torácica, dois para a lordose lombar além de sete casos de escoliose. Não foi fixado um único jeito para mensurar a lordose lombar nem cifose torácica, decorrendo assim uma maior quantidade de ângulos gerados, sendo assim mais interessante para demonstrar a correlação de ambos os métodos.

Os ângulos obtidos para a cifose torácica e lordose lombar por ambos os métodos foram muito próximos, algo que pode ser visto na Tabela 3. As médias, desvios padrões e intervalos quase se equiparam. Os coeficientes de correlação de Pearson encontrados são muito fortes, variando de 0,97 a 0,99. No caso da escoliose os resultados foram muito satisfatórios também, visto que a correlação foi

\footnotetext{
${ }^{10}$ Lembrando que os dados obtidos para os dois métodos, Cinemetria e LoB Analytics são os mesmo; foram marcados pelo mesmo fisioterapeutas e colhidos simultaneamente.

${ }^{11}$ Dezoito ângulos de cifose torácica utilizando os processos espinhosos referentes as vértebras $\mathrm{C}_{7} \mathrm{e}$ $T_{12}$, dezoito utilizando $T_{1}$ e $T_{12}$ e mais dezoito utilizando $T_{2}$ e $T_{12}$. Para a lordose lombar foram mais dezoito ângulos utilizando T10 e S2 e dezoito com T12 e S2. Já para a escoliose não tem um sistema de parâmetros definido, e foram ao todo sete ângulos medidos.
} 
0,94 e seis diferenças absolutas entre os ângulos metidos pelos dois métodos foram menores que $2^{\circ}$, tendo um caso apenas que ficou em $3^{\circ}$ de diferença.

Para enxergar melhor a diferença entre os métodos foi construída a Tabela 5. Nela percebe que a maioria (55,7\%) dos ângulos diferenciou até apenas 3․ Se for utilizado o intervalo usado por Leroux et. al. (2000) e Bernhardt et. al.(1989), que definiram um erro de 5ำ para a confiabilidade dos métodos, 87 diferenças absolutas $(89,7 \%)$ foram menor que 5o; 8 ficaram entre $5^{\circ}$ e $10^{\circ}$ (8,3\%); e apenas 2 casos $(2,0 \%)$ apresentaram diferença absoluta maior que $10^{\circ}$. São números bastante expressivos visto que a maior incidência relativa de ângulos com diferença absoluta menor que $5^{\circ}$ foi $56,0 \%$, encontrado por Leroux et. al.(2000).

Encontrada uma correlação forte e ângulos muito próximos, uma próxima análise foi realizada a fim de detectar se há alguma tendência na medição feita pelo LoB Analytics. Foi comparado os ângulos medidos entre os métodos e $57,4 \%$ dos medidos pelo $L O B$ Analytics apresentaram valores maiores que os medidos através da Cinemetria (Tabela 6). Como o espaço amostral é pequeno, é difícil que ocorra uma distribuição binomial perfeita demonstrando que não há uma tendência dos ângulos medidos pelo Lob Analytics serem maiores, porém 57,4\% é um número bem próximo dos $50 \%$. Para verificar melhor se há ou não essa tendência, foram feitas regressões lineares dos ângulos calculados.

Para os ângulos da cifose torácica utilizando $C_{7} \sim T_{12}$ e $T_{1} \sim T_{12}$ foram achados

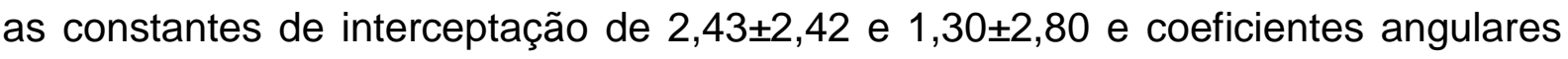
de $0,96 \pm 0,05$ e 0,97 $\pm 0,06$ respectivamente. Essas constantes, junto com o coeficiente angular mostram a distribuição binomial dos dados, tirando a hipótese de tendência do LoB Analytics (Figura 24 e Figura 25). Para a escoliose também foi descartada a hipótese de tendência com a regressão linear, obtendo uma constante de interceptação de $-1,49 \pm 3,70$ com um coeficiente angular de 1,05 $\pm 0,17$ (Figura 29). Para esses casos, assumindo o desvio padrão, todos demonstram uma linearidade perfeita.

Para a cifose torácica utilizando $T_{2}$ e $T_{12}$ foram encontrados 5,30 2,78 de

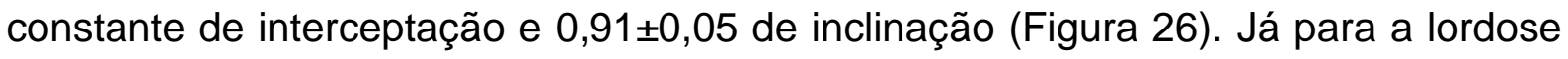




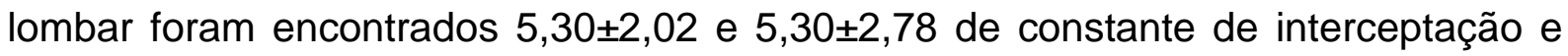

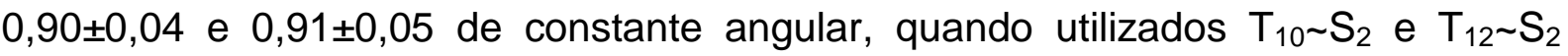
respectivamente (Figura 27 e Figura 28).

O mesmo ocorre quando se junta todos os ângulos calculados para fazer a regressão linear, encontrando $3,81 \pm 0,86$ e $0,94 \pm 0,02$ para a constante de interceptação e angular respectivamente (Figura 30) - além de uma correlação de 0,98 e uma média de $43,4 \pm 18,5^{\circ}$ para os ângulos vindo da cinemetria e $43,9 \pm 17,7^{\circ}$ para os do LoB Analytics.

A partir dessas informações nota-se que há uma leve tendência que os ângulos do $L O B$ Analytics sejam maiores que os da Cinemetria - algo em torno dos $2^{\circ}$. Essa acentuação para cima pode ser causada pelos marcadores utilizados, visto que são esféricos. Pode-se optar por usar marcadores planos - uma fita ou mesmo uma marca de caneta nos processos espinhosos - para que não ocorra do usuário clicar ora em um lugar da esfera ora em outro.

\section{CONCLUSÃO}

Outros estudos apresentados mostram a validação da Cinemetria como método para mensurar a curvatura da coluna vertebral, identificando assim casos de hiper e hipocifoses, hiper e hipolordose e escoliose.

Esse estudo usou essa validação como ponte para comparação do software livre desenvolvido aqui, chamado de $L O B$ Analytics. Foram ao todo dezoito indivíduos e 97 ângulos, sejam eles de cifose, lordose ou escoliose, medidos simultaneamente com a Cinemetria e com o LOB Analytics. A média de todos os ângulos obtida pela Cinemetria foi de $43,4 \pm 18,5^{\circ}$ e pelo $\operatorname{LoB}$ Analytics foi de $43,9 \pm 17,7^{\circ}$, com uma correlação muito forte de 0,98 .

Tendo essa correlação, foi feito uma análise para ver se havia alguma tendência nos ângulos obtidos pelo $L O B$ Analytics. Uma análise simples foi feito pelo número de vezes em que o ângulo calculado pelo $L O B$ Analytics foi maior que pela 
Cinemetria: $57,4 \%$ das vezes. Uma regressão linear foi feita para checar mais precisamente essa possível tendência. Quando se tratou de medir a lordose lombar foi verificada que a linearidade não era tão perfeita como verificado pra cifose e escoliose, sendo observado que o LOB Analytics calcula os ângulos em 1ำ a $2^{\circ}$ acima dos ângulos da Cinemetria. Essa diferença é muito pequena quando se trata de ângulos cuja média foi $48,7^{\circ}\left(48,6^{\circ}\right.$ usando $T_{10^{\sim}} \sim S_{2}$ e $48,8^{\circ}$ usando $\left.T_{12^{\sim}} \sim S_{2}\right)$.

Estudos futuros podem identificar a obtenção de ângulos através de avaliadores diferentes a fim de verificar se há uma correlação interclasse.

Esses resultados mostram que os ângulos calculados pelo $\operatorname{LoB}$ Analytics são tão confiáveis quanto os calculados pela Cinemetria, que é um método bastante utilizado hoje em dia. Os grandes diferenciais do $L O B$ Analytics sobre a Cinemetria são: o seu baixo custo e a praticidade de usá-lo em laboratórios e clínicas.

O LoB Analytics está disponível em:

\section{http://sourceforge.net/projects/lobanalytics/}




\section{REFERÊNCIAS BIBLIOGRÁFICAS}

ABDEL-AZIZ , Y. I. \& KARARA, H. M. Direct linear transformation from comparator coordinates into object-space coordinates in close-range photogrammetry. In Symposium on Close-Range Photogrammetry, Urbana Champaign, Illinois, p. 1-18, 1971.

BARAÚNA, M.A.; CANTO, R.S.T.; SANCHEZ, H.M.; BUSTAMANTE, J.C.F; Validade e confiabilidade intra-indivíduo do cifolordômetro na avaliação da convexidade torácica. Rev Bras Fis. v. 9(3): p. 319-25, 2005.

BERNHARDT, M.; BRIDWELL, K.H. Segmental analysis of the sagittal plane alignment of the normal thoracic and lumbar spines and thoracolumbar junction. Spine, v. 14, n. 7, p. 717-21, July 1989.

BEER, F. P.; JOHNSTON JR., E. R. Mecânica vetorial para engenheiros: cinemática e dinâmica. 5aㅡ ed. São Paulo: Makron Books, 1991.

BIOT, B.; BERNARD, J. C.; MARTY, C.; TOUZEAU, C.; STORTZ, M. Escoliosis. Encyclopèdie Médico-Chirurgicale, Paris, n. 82, p. 01-06, 2002.

BOGDUK, N. Clinical anatomy of the lumbar spine and sacrum. $3^{a}$ ed., New York: Churchill Livingstone, 1997.

BRADFORD, D.S.; LONSTEIN, J.E.; MOE J.H.; OGIVIE, J.W.; WINTER, R.B. Escoliose e outras deformidades da coluna: o livro de moe., $2^{\underline{a}}$ ed., Santos, SP, 1994.

BUNNEL, W.P. An objective criterion for scoliosis screening. The Journal of Bone and Joint Surgerv. n.66-A, p. 1381-7, 1984.

BUSTAMANTE, J.C.F. Avaliação da convexidade torácica através da cifolordometria. Uberlândia. Dissertação (Mestrado em Fisioterapia) - Centro Universitário do Triângulo, 2002. 
CAILLIET, R. Escoliose diagnóstico e tratamento. São Paulo: Manole, 1979.

CAMPBELL-KYUREGHYAN, N.; JORGENSEN, M.; BURR, D.; MARRAS, W. The prediction of lumbar spine geometry: method development and validation. Clin. Biomech., Bristol, v. 20, n. 5, p. 455-64, June 2005.

CAMPOS, M.H. - Adaptações geométricas da coluna durante a marcha. Campinas. Dissertação (Mestrado em Educação Física) - UNICAMP, 2005.

CHEN Y.L.; LEE Y.H. - A non-invasive protocol for the determination of lumbosacral vertebral angle. Clin Biomech. n. 12, p. 185-9, 1997.

D'OSUALDO F.; SCHERANO S.; IANNIS M. Validation of clinical measurement of kyphosis with a simple instrument, the arcometer. Spine. n. 22, p. 408-13, 1997.

DESCARREAUX M.; BLOUIN J.S.; TEASDALE N. - A non-invasive technique for measurement of cervical vertebral angle: report of a preliminary study. European Spine Journal. n. 12, p. 314-9, 2003.

DUTKOWSKY, J.P.; SHEARER, D.; SCHEPPS, B.; ORTON, C.; SCOLA, F. Radiation exposure to patients receiving routine scoliosis radiography measured at depth in an anthropomorphic phantom. J. Pediatr. Orthop., New York, v. 10, n. 4, p. 532-4, Aug. 1990.

EVCIK, D.; YUCEL, A. Lumbar lordosis in acute and chronic low back pain patients. Rheumatol. Int., v. 23, n. 4, p. 163-5, July 2003.

FERREIRA, D.M.A. Estudo clínico da mensuração da gibosidade e suas correlações com medidas radiológicas na escoliose idiopática. Dissertação (Mestrado em Bioengenharia) - USP, Ribeirão Preto, 1999.

FON, G; PITT, M; THIES, A. Thoracic kyphosis: range in normal subjects. A J R n. 134: p 979-83, 1980. 
GELB, D.E.; LENKE, L.G.; BRIDWELL, K.H.; BLANKE, K.; McENERY, K.W. An analysis of sagittal spinal alignment in $\mathbf{1 0 0}$ asymptomatic middle and older aged volunteers. Spine, v. 20, n. 12, p. 1351-8, June 1995.

HEBERT, S.; XAVIER, R.; PARDINI JR., A.G.; BARROS FILHO, T.E. Ortopedia e traumatologia princípios e prática, $2^{\mathrm{a}}$ ed. Porto Alegre: Artmed, 1998.

KENDALL, F. P.; MCCREARY, E.K.; PROVANCE, P.G. Músculos Provas e Funções, São Paulo: Manole, 4⿳亠丷a ed., 1995.

KOROVESSIS, P.; PETSINIS, G.; PAPAZISIS, Z.; BAILLOUSIS, A. Prediction of thoracic kyphosis using the De Brunner kyphometer. J Spin Disor. 14(1): 67-72, 2001.

KYUREGHYAN, N; JORGENSEN, M; BURR, D; MARRAS, W. The prediction of lumbar spine geometry: method development and validation. Clin Biomech., $\mathrm{n}$. 20: 455-64, 2005.

LEROUX, M.A.; ZABJEK, K.; SIMARD, G.; BADEAUX, J.; COILLARD, C.; RIVARD, $\mathrm{C} . \mathrm{H}$. A noninvasive anthropometric technique for measuring kyphosis and lordosis: an application for idiopathic scoliosis. Spine, v. 25, n. 13, p. 1689-94, July 2000.

LIMA, J. Diagnóstico radiológico em Fisioterapia. Apostila do curso Diagnóstico por imagem para fisioterapeutas, Cascavel, set., 2002.

LOUBRESSE, C.; VIALLE, R.; WOLFF, S. Cyphosis pathologiques EMC, Rhumatologie orthopédie. Article in press, 2005.

LUNDON, K.; LI, A.; BIBERSHTEIN, S. Interrater and Intrarater Reliability in the Measurement of Kyphosis in Postmenopausal Women With Osteoporosis. Spine. 23(18): 1978-1985, 1998. 
NISSINEN, M. Spinal posture during pubertal growth. Acta Paediatr., Stochkhom, v. 84, n. 3, p. 308-12, Mar. 1995.

NORMAND, M.C.; HARRISON, D.E.; CAILLIET, R.; BLACK, P.; HARRISON, D.D.; HOLLAND, B. - Reliability and measurement error of the biotonix video posture evaluation system - part I: inanimate objects. Journal of Manipulative and Physiological Therapeutics. n. 5, p. 246-50, 2002.

MANNION, A.; KNECHT, K.; BALABAN, J. E.; GROB, D. A new skin-surface device for measuring the curvature and global and segmental ranges of motion of the spine: realiability of measurements and comparison with data reviewed from the literature. Eur Spine J. 13: 122-36, 2004.

McGILL, S.M.; HUGHSON, R.L.; PARKS, K. Changes in lumbar lordosis modify the role of the extensor muscles. Clin. Biomech., Bristol, v. 15, n. 10, p. 777-80, Dec. 2000.

MEDEIROS, R.B.; DAROS, K.A. Avaliação das doses de radiação $\mathbf{X}$ recebidas por pacientes em estudos radiológicos. Radiologia Brasileira, v. 30, p. 263-5, 1997.

NIGG, B. M. \& HERZOG, W. Biomechanics of the musculo-skeletal system. Chichester, Wiley \& Sons, 1994.

PANJABI, M.M; WHITE, A.A. III. Basic biomechanics of the spine. Neurosurgery, v. 7, n. 1, p. 76-93, July 1980.

PEARSALL, D.J.. REID J.G.; HEDDEN, D.M. Comparison of three noninvasive methods for measuring, scoliosis. Physical Therapy. n. 72, p. 648-57, 1992.

POOLMAN, R.; BEEN, H.; UBAGS L. Clinical outcome and radiographic results after operative treatment of Scheuermann's disease. Eur Spine J., n. 11: 561-9, 2002. 
PROPST-PROCTOR, S.L.; BLECK, E.E. Radiographic determination of lordosis and kyphosis in normal and scoliotic children. J. Pediatr. Ortop., New York, v. 3, n. 3, p. 344-6, July 1983.

RIBEIRO, C. Z. P.; AKASHI, P. M. H.; SACCO, I. C. N.; PEDRINELLI, A. Relationship between postural changes and injuries of the locomotor system in indoor soccer athletes. Rev Bras Med Esporte, n. 9, 2003.

RICARD, F. Las escoliosis. Tratado de Radiologia Osteopática del Raquis, Madrid: Panamericana, p. 269-77, 1999.

ROUSSOULY, P.; GOLLOGLY, S.; BERTHONNAUD, E.; DIMNET, J. Classification of the normal variation in the sagittal alignment of the human lumbar spine and pelvis in the standing position. Spine, v. 30, n. 3 , p. 346-53, Feb. 2005

SAR, C.; ERALP, L. Three-stage surgery in the management of severe rigid angular kyphosis. Eur Spine J., n. 11: 107-14, 2002.

SCHROTH, C. L. Introduction to the three-dimensional Scoliosis treatment according to Schroth. Physiotherapy, Londres, v. 78, n. 11, p. 810-5, nov., 1992.

SINGER, K.P.; JONES, T.J.; BREIDAHL, P.D. A comparison of radiographic and computer-assisted measurements of thoracic and thoracolumbar sagittal curvature. Skeletal Radiol., Salzburg, v. 19, n. 1, p. 21-6, 1990.

Skaggs, D.L.; Bassett, G.S. Adolescent idiopathic scoliosis: an update. American Family Physician, n. 53, p. 23-7, 1996.

SOUZA, F.R. Avaliação da concavidade lombar pelo método radiográfico e pela cifolordometria, 2006. Dissertação (Mestrado em Fisioterapia) - UNITRI, Uberlândia. 
STAGNARA, P.; De MAUROY, J.C.; DRAN, G.; GONON, G.P.; COSTANZO, G.; DIMNET, J.; PASQUET, A. Reciprocal angulation of vertebral bodies in a sagittal plane: approach to references for the evaluation of kyphosis and lordosis. Spine, v. 7, n. 4, p. 335-42, July-Aug. 1982.

TEIXEIRA, F.A. Validação do método flexicurva para avaliação angular da cifose torácica, 2006. Dissertação (Mestrado em Educação Física) - Universidade Católica de Brasília, Brasília.

VEDANTAM, R.; LENKE, L.G.; KEENEY, J.A.; BRIDWELL, K.H. Comparison of standing sagittal spinal alignment in asymptomatic adolescents and adults. Spine, v. 23, n. 2, p. 211-5, Jan. 1998.

VIALLE, R.; LEVASSOR, N.; RILLARDON, L.; TEMPLIER, A.; SKALLI, W.; GUIGUI, $P$. Radiographic analysis of the sagittal alignment and balance of the spine in assyntomatic subjects. J. Bone Joint Surg. Am., v. 87, n. 2, p. 260-7, Feb. 2005.

VOUTSINAS, S.A.; MacEWEN, G.D. Sagittal profiles of the spine. Clin. Orthop. Relat. Res., Wilmington, n. 210, p. 235-42, Sept. 1986.

WILLNER, S. Spinal pantograph: a non-invasive technique for describing kyphosis and lordosis in the thoraco-lumbar spine. Acta Orthop Scand. n. 52, p. 525-9, 1981.

Zar, J.H. Biostatistical Analysis, Prentice-Hall, 1999. 


\title{
ANEXO I - TERMO DE CONSENTIMENTO LIVRE E ESCLARECIDO
}

\author{
PROJETO: "Desenvolvimento e validação de uma ferramenta computacional para \\ mensuração das curvaturas da coluna vertebral " \\ Pesquisador responsável: Prof. Dr. Marcos Duarte \\ Pesquisador gerente: André Luis Alarcon do Passo Suaide
}

TERMO DE CONSENTIMENTO LIVRE E ESCLARECIDO

\section{DADOS DE IDENTIFICAÇÃO DO SUJEITO:}

NOME:

DOCUMENTO DE IDENTIDADE №:

SEXO: $\quad M \square F \square$

DATA NASCIMENTO:

ENDEREÇO:

№

APTO.

BAIRRO:

CIDADE:

CEP:

TELEFONE:

)

TELEFONE (RECADO):

\section{DECLARAÇÃO DE CONSENTIMENTO:}

Declaro que concordo em participar da pesquisa: "Desenvolvimento e validação de uma ferramenta computacional para mensuração das curvaturas da coluna vertebral" conduzida pelo mestrando André Luis A. do P. Suaide e pelo Prof. Dr. Marcos Duarte, a qual será realizada na Escola de Educação Física e Esportes da Universidade de São Paulo (EEFE-USP).

\section{Objetivo do Estudo:}

Desenvolver um método simples, barato e não invasivo para a medição da curvatura da coluna vertebral, identificando assim possíveis hiperlordoses, hipercifoses e escolioses. Um software foi desenvolvido especialmente para a análise dessas patologias.

\section{Procedimento:}

Durante o experimento ficar imóvel em um ambiente apropriado dentro do Laboratório de Biofísica da EEFE-USP. Pequenas marcas serão afixadas na minha pele por uma fita dupla-fase de fácil remoção para registrar os processos espinhosos da minha coluna vertebral. Ficarei sem camisa para que um fisioterapeuta identifique meus processos espinhosos. Uma foto será tirada das minhas costas. Estou ciente que posso usar um top ou um maiô para não deixar a parte de cima totalmente desnuda.

Minhas fotos servirão para posterior análise, mas minha imagem não será utilizada para outros fins que não esse estudo.

\section{Duração do Experimento:}

Cada experimento terá a duração de aproximadamente 30 minutos. 


\section{Benefícios:}

O estudo disponibilizará uma ferramenta que poderá ser usada e modificada livremente e gratuitamente em outros estudos e em clínicas por profissionais para identificação das patologias ditas no objetivo.

\section{Desconfortos e Riscos:}

Fui informado que o experimento não será invasivo, e que não envolve qualquer risco à minha saúde física e mental, além dos riscos encontrados nas atividades normais da minha vida diária.

\section{Liberdade de Participação:}

A minha participação nesse estudo é voluntária e tenho direito de interrompê-la a qualquer momento. Tenho direito de fazer qualquer pergunta nos intervalos do experimento.

Os pesquisadores me explicaram todos os riscos envolvidos, a necessidade da pesquisa e se prontificaram a responder todas as questões sobre o experimento. Também me informaram que minha identidade não será revelada.

Eu aceitei participar desse estudo de livre e espontânea vontade e é meu direito manter uma cópia desse consentimento.

Para questões associadas com esse experimento, por favor, entrar em contato com André Luis Suaide e/ou Prof. Dr. Marcos Duarte, coordenador do Laboratório de Biofísica.

Rua Professor Melo Moraes, 65 - Cidade Universitária - CEP: 05508-030 - fone/fax: 3812-6123 